Jurisprudencia Serie Semilleros

\title{
Los derechos humanos
}

y la

democracia

en la era

digital

\section{María Lucía Torres-Villarreal \\ Paola Marcela Iregui-Parra \\ —Editoras académicas_-}

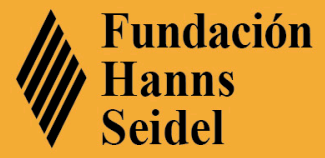


》 $\begin{aligned} & \text { Fundación } \\ & \text { Hanns } \\ & \text { Seidel }\end{aligned}$

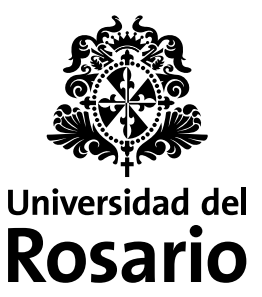





\section{Los derechos humanos y la democracia en la era digital}




\title{
Los derechos humanos y la democracia en la era digital
}

\section{Resumen}

El objetivo de esta obra es publicar las mejores ponencias ganadoras del viır Concurso Nacional de Semilleros: "La protección de los derechos humanos y la democracia en la era digital", con el fin de seguir así enriqueciendo el debate académico con la investigación realizada por los estudiantes en temas de actualidad jurídica, política y social. Como desde hace ya seis años, con el ejercicio pedagógico de este Concurso se observaron los resultados y la importancia de la investigación formativa en las facultades de Derecho y todas las carreras afines, y el presente libro es prueba de esto.

Palabras clave: Derechos Humanos, desarrollo, democracia, Internet, ciberacoso.

\section{Human Rights and Democracy in the Digital Era}

\begin{abstract}
This collection publishes the winning presentations in the Seventh National Young Scholars Contest: The protection of Human Rights and democracy in the digital era. The research conducted by students on the current state of legal, social, and political matters facing Colombian society, represented in these texts, will enrich ongoing debates on these topics. This collection provides ample evidence that the lessons learned a result of this year's contest, as in the contests over the last five years; demonstrate the results and the importance of formative research in Law Schools and related fields of study.
\end{abstract}

Key words: Human Rights, development, democracy, Internet, cyberbullying. nos y la democracia en la era digital. Bogotá: Editorial Universidad del Rosario, Fundación Hanns Seidel.

DOI: doi.org10.12804/js9789587841954 


\title{
Los derechos humanos y la democracia en la era digital
}

\author{
María Lucía Torres-Villarreal \\ Paola Marcela Iregui-Parra \\ -Editoras académicas-
}


Torres-Villarreal, María Lucía

Los derechos humanos y la democracia en la era digital / María Lucía Torres-Villarreal; Paola Marcela Iregui-Parra, editoras académicas - Bogotá: Editorial Universidad del Rosario y

Fundación Hanns Seidel, 2018.

xiv, 86 páginas.

Incluye referencias bibliográficas.

Derechos humanos / Victimología / Delitos contra la persona / Educación por internet / Cambio social-Colombia / trabajo social con homosexuales / Acoso escolar-investigaciones (Colombia) / I. Universidad del Rosario. / II. Fundación Hanns Seidel / III. Título / IV. Serie.

323.01861 SCDD 20

Catalogación en la fuente - Universidad del Rosario. CRAI

Hecho el depósito legal que marca el Decreto 460 de 1995

\section{Universidad del Rosario}

Jurisprudencia

(C) Editorial Universidad del Rosario

(C) Universidad del Rosario

(C) Fundación Hanns Seidel

(C) Varios autores

(C) María Lucía Torres V.y Paola Marcela Iregui, por la Presentación

Editorial Universidad del Rosario Carrera 7 No. 12B-41, of. 501

Tel: 29702 00, Ext. 3112

editorial.urosario.edu.co

\section{Fundación Hanns Seidel}

Primera edición: Bogotá D. C., 2018

ISBN: 978-958-784-194-7 (impreso)

ISBN: 978-958-784-195-4 (ePub)

ISBN: 978-958-784-196-1 (pdf)

DOI: doi.org/10.12804/js9789587841954

Coordinación editorial:

Editorial Universidad del Rosario

Corrección de estilo: María José Molano Valencia Diseño de cubierta y diagramación:

Precolombi EU-David Reyes

Impresión: Xpress. Estudio Gráfico y Digital S.A.S.

Impreso y hecho en Colombia

Printed and made in Colombia

Los conceptos y opiniones de esta obra son de exclusiva responsabilidad de sus autores y no comprometen a la universidad ni sus políticas institucionales.

El contenido de este libro fue sometido al proceso de evaluación de pares, para garantizar los altos estándares académicos. Para conocer las políticas completas visitar: editorial.urosario.edu.co

Todos los derechos reservados. Esta obra no puede ser reproducida sin el permiso previo escrito de los editores. 


\section{Contenido}

Presentación ............................................................... xi

María Lucia Torres $V$.

Paola Marcela Iregui P.

Derechos fundamentales y ciberbullying para colegios públicos urbanos de Duitama (Boyacá).

Protocolo de actuación: procedimientos disciplinarios....... 1

Giovana Andrea Neita Carreño

Yulieth Catalina Reina Gutiérrez

1. Introducción ............................................................... 3

2. Metodología.................................................................. 7

2.1. Tipo de estudio y enfoque …................................... 7

2.2. Duitama ................................................................ 7

2.3. Población y muestra................................................... 8

2.4. Instrumentos .......................................................... 9

3. Avances, resultados, discusión ......................................... 9

3.1. Significado de ciberbullying y su prevalencia a nivel mundial ...................................................... 9

3.2. Estudios llevados a cabo ......................................... 12

3.3. Determinar qué conductas constituyen ciberbullying y cuáles pueden catalogarse como delito en Colombia ....................................... 15 
3.4. Normatividad relacionada con el ciberbullying a nivel nacional teniendo en cuenta la Ley de Infancia y Adolescencia, el código penal y el código civil

3.5. Procedimientos disciplinarios en colegios y diseño de cartilla 26

4. Conclusiones............................................................. 26

Referencias .......................................................... 27

\section{Población LGTBI en contextos penitenciarios:} retos de actuación en el uso de las nuevas tecnologías para las ciencias sociales

Luis Felipe Cardona Herrera

1. Introducción ............................................................. 35

2. Metodología ................................................................. 38

3. Marco teórico.......................................................... 41

3.1. Comunidad LGTBi: una mirada desde la realidad penitenciaria y carcelaria colombiana .................... 45

4. Conclusiones............................................................ 55

Referencias .......................................................... 57

\section{\#ClicSocial}

Participación digital para la inclusión social

Melissa Morales Londoño

Brigit Joaly Zapata Muñoz

1. Introducción

1.1. Análisis de la participación ciudadana desde las Clínicas Jurídicas

1.2. De la ciudadanía

1.3. Movilización social a través de los medios de comunicación. 
1.4. Análisis respecto de las personas con diversidad funcional............................................. $\quad 70$

1.5. \#ClicSocial, un paso hacia la transformación........... 73

2. Metodología.................................................................. 80

3. Conclusiones.............................................................. 81

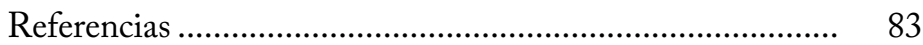





\section{Presentación}

Cuando pensamos en las condiciones en que se desarrollan muchos escenarios de la democracia actual, cuando se analiza cómo se hace uso de los mecanismos de participación hoy en día y el sinnúmero de situaciones en las que se cuestionan abiertamente las formas clásicas de manejo del poder, de interacción con los administrados, de conducción de relaciones con países vecinos, de desarrollo del comercio transfronterizo y, más allá de todo, de materialización de los derechos, nos enfrentamos a una realidad: ¿cómo se protegen los derechos humanos en la era digital, en la cual ya está sumido el modelo democrático y sus formas?

Por muchos años, la democracia parecía seguir sometida a conceptos clásicos de soberanía, territorio y ciudadanía; pero por mayor resistencia que se ejerciera, el modelo de Estado evolucionó y empezaron a imperar situaciones donde las fronteras entre estados se flexibilizaban - para algunas situaciones-, planteando escenarios de legislaciones y autoridades trasnacionales, organismos supranacionales y, con ello, conceptos como ciudadanos del mundo, gobierno en línea $\mathrm{y}$ muchos otros que enfrentaban al ciudadano tradicional a un mundo globalizado. 
El VIII Concurso Nacional de Semilleros de Investigación, organizado por la Universidad del Rosario por conducto de su Grupo de Investigación en Derechos Humanos y de su Observatorio Legislativo, en asociación con la Fundación Hanns Seidel, tuvo como tema central "La protección de los derechos humanos y la democracia en la era digital", con el fin de conocer las temáticas que en el marco de las nuevas tecnologías de la información (TIC) bordeaban las nociones de derechos humanos y sus elementos de garantía y protección.

En los últimos años, el tema ha adquirido especial relevancia y por ello decidimos enfocar los esfuerzos de esta versión del Concurso en indagar por estos "nuevos temas" que terminan incluyendo diversas ramas de las ciencias sociales y, especialmente, nociones clásicas del derecho en muchas de sus áreas de conocimiento, generando efectos directos en los elementos esenciales del modelo democrático y que no siempre implican escenarios positivos de cara a los derechos o al ciudadano de a pie. De cualquier manera, en muchas perspectivas pareciera ser un tema cultural o generacional, pero claramente en virtud de la globalización se ha apoderado de muchos espacios.

A pesar de tratarse de una cuestión quizás no muy frecuente o recurrente en las investigaciones adelantadas en la Academia, registramos un total de 37 ponencias enviadas a la fase escrita del concurso, provenientes de diversas regiones del país, con interesantes ideas para enmarcar investigaciones tradicionales en estos escenarios y otras muy concretas que versaban sobre aspectos ya más estrechamente relacionados con el tema. Esto para señalar que no solo fue un concurso marcado por la investigación como principal habilidad que pretende fortalecerse con este tipo de escenarios académicos, sino que se implementaron competencias y destrezas de 
creatividad, conexión temática, argumentación y, sin duda, se notó un interés de las nuevas generaciones de investigadores presentes en semilleros de investigación formativa por adelantar estudios en temas coyunturales, novedosos, ligados a los derechos y su relación con la globalización y la democracia en la era digital.

De esa manera, las ponencias pasaron al proceso de revisión de pares, para lo cual se escogieron profesores y expertos con altas calidades académicas e investigativas, quienes, a partir de unos parámetros de forma y de fondo establecidos por el comité académico del concurso, evaluaron las ponencias y seleccionaron trece que pasaron a la siguiente ronda, es decir, a la ronda oral que se llevaría a cabo en la Universidad del Rosario los días 10 y 11 de mayo del 2018.

Las ponencias versaban sobre variados e interesantes temas que se pueden estructurar en tres grandes ejes temáticos: i) Democracia y derechos emergentes, tratando temas de redes sociales, soft power y nuevos alcances de los derechos o, más bien, situaciones que plantean nuevos esquemas de derechos; ii) Grupos de especial protección y tecnologías, abarcando escenarios como el de la migración, la discapacidad, la comunidad LGTBI, entre otros y su estrecha relación con las TIC; y iii) Transformaciones de la democracia de cara a los derechos tradicionales, abordando temas como la libertad, la integridad, la igualdad y los elementos constitutivos del modelo democrático.

El Semillero de Investigación de la Universidad Antonio Nariño, Sede Duitama, obtuvo el primer lugar de la competencia con una ponencia titulada Derechos fundamentales y ciberbullying para colegios públicos urbanos de Duitama; el segundo puesto lo obtuvo la Universidad Libre, Seccional Pereira, con la ponencia Población LGBTI en contextos 
penitenciarios: retos de actuación en el uso de las nuevas tecnologías para las ciencias sociales; y en el tercer puesto la ponencia \#ClicSocial. Participación digital para la inclusión social.

Por octavo año consecutivo, la Universidad del Rosario y la Fundación Hanns Seidel cumplieron con su objetivo de fomentar la investigación desde los procesos de formación que se adelantan en las universidades, con el ánimo de cimentar y fortalecer en los profesionales del mañana una serie de habilidades y competencias que se requieren para atender la complejidad de las situaciones del contexto actual y de la coyuntura de Colombia y del mundo. De igual manera, se continúa incentivando la investigación en las universidades regionales, reconociendo que las capacidades de nuestros estudiantes no se concentran solo en instituciones de las grandes ciudades sino también en las regiones, donde se viven muchas problemáticas que, si no fuese por este tipo de escenarios, no tendrían forma de ser visibilizadas.

Seguiremos, año tras año, buscando orientar nuestros esfuerzos a la búsqueda de temáticas de especial relevancia para la investigación y para el país, pues estamos convencidos de que a partir de esta y de las herramientas con las que cuenta para su materialización se pueden realizar importantes aportes para la construcción de un mejor país.

María Lucía Torres V. Directora Observatorio Legislativo Profesora Grupo de Investigación en Derechos Humanos Universidad del Rosario

Paola Marcela Iregui P. Profesora Grupo de Investigación en Derechos Humanos Universidad del Rosario 


\title{
Derechos fundamentales y ciberbullying para colegios públicos urbanos de Duitama (Boyacá) Protocolo de actuación: procedimientos disciplinarios ${ }^{*}$
}

\author{
Giovana Andrea Neita Carreño** \\ Yulieth Catalina Reina Gutiérrez****
}

\section{Resumen}

Las tecnologías de la información han tenido un impacto negativo en conductas que atentan contra los derechos fundamentales de los niños, niñas y adolescentes. Los estudiantes no suelen reconocer el ciberbullying como delito; por lo

* Hacemos un reconocimiento especial al doctor César Alfonso Díaz Pacheco, docente de la Universidad Antonio Nariño de Duitama, Boyacá, Colombia, quien nos guió en la dirección de este trabajo.

*** Estudiante de primer semestre de Derecho en la Universidad Antonio Nariño de Duitama, Boyacá, Colombia. Grupo de investigación Iustitia, Semillero Construyendo Soluciones. Correo electrónico: gneita84@uan.edu.co.

*** Estudiante de primer semestre de Derecho en la Universidad Antonio Nariño de Duitama, Boyacá, Colombia. Correo electrónico: yreina46@uan.edu.co. 
tanto, no son conscientes de las repercusiones psicológicas o legales que tienen los actos que realizan dentro del ciberespacio para los demás ni para ellos mismos. Es de resaltar que los agresores se aprovechan y siguen acosando ante la falta de castigos.

El objetivo general de esta investigación es diseñar un protocolo de actuación con procedimientos disciplinarios que garanticen el cumplimiento de los derechos fundamentales de los estudiantes en los colegios públicos urbanos de Duitama, y es un trabajo pertinente porque es necesario privilegiar la cultura de paz en instituciones educativas. E1 tipo de estudio empleado es analítico-descriptivo y con un enfoque sociojurídico. Como resultado, por una parte, se estableció el significado de ciberbullying y su prevalencia a nivel mundial y, por la otra, se determinaron las conductas que lo constituyen. Además, en los países objeto de estudio se encontró una alta prevalencia del ciberbullying en la última década. Actualmente se están identificando los procedimientos disciplinarios de los colegios y se avanza en los demás objetivos específicos.

Palabras clave: ciberbullying, protocolo, derechos fundamentales, procedimientos disciplinarios.

\section{Abstract}

Information technologies have had a negative impact on behaviours that threaten the fundamental rights of children and adolescents. Students often do not recognize cyberbullying as a crime; therefore, they are not aware of the psychological or legal implications that those acts have in cyberspace for others or even for themselves. The general objective is to design a protocol of actions with disciplinary procedure 
to guarantee the compliance of the fundamental students' rights in the urban public schools in Duitama. The type of study is analytical descriptive focus with a socio-legal. As a result the meaning of cyberbullying is settled its prevalence worldwide, and the actions that constitute the CB are determined. The countries studied show a high prevalence of $\mathrm{CB}$ in the last decade. Nowadays, the project is identifying the disciplinary procedures of schools and is moving on the other specific objectives.

Key words: cyberbullying, protocol, fundamental rights, disciplinary procedures.

\section{Introducción}

Las tecnologías de la información han tenido un impacto negativo en conductas que atentan contra los derechos fundamentales de las personas, como la honra y la dignidad, entre otros, al potenciar el daño causado por los ataques y los acosos que sufren los estudiantes. Es de anotar que los estudiantes no suelen reconocer la violencia virtualy, por lo tanto, no son conscientes de las repercusiones psicológicas o legales que tienen los actos que realizan dentro del ciberespacio, ni para los demás ni para ellos mismos.

Ahora bien, los niños, niñas y adolescentes (NNA) son sujetos de derecho y deben ser formados para el análisis y recepción de contenidos en los medios tecnológicos. Las políticas educativas deben darles protagonismo a los estudiantes para que se expresen y reflexionen sobre las nuevas tecnologías de la información y la comunicación para la construcción de ciudadanía. Por lo tanto, es necesario analizar el derecho a la información, a la libre expresión y así 
mismo el derecho a la no intromisión en la vida privada, en la familia y el domicilio, ni de ataques a la honra y su reputación, como lo establece la Declaración Universal de los Derechos Humanos (2017) en los artículos 12 y 19:

Artículo 12. Nadie será objeto de injerencias arbitrarias en su vida privada, su familia, su domicilio o su correspondencia, ni de ataques a su honra o a su reputación. Toda persona tiene derecho a la protección de la ley contra tales injerencias o ataques.

Artículo 19. Todo individuo tiene derecho a la libertad de opinión y de expresión; este derecho incluye el no ser molestado a causa de sus opiniones, el de investigar y recibir informaciones y opiniones, y el de difundirlas, sin limitación de fronteras, por cualquier medio de expresión.

Es de anotar que no siempre se logra la reparación efectiva de los daños sufridos por las víctimas de ciberbullying, por lo que son necesarias medidas adicionales, razón por la que los padres generalmente terminan por retirar de la institución educativa a su hijo víctima.

Tomando como base el trabajo realizado entre los años 2014 y 2017 en el Instituto Técnico Industrial Rafael Reyes de Duitama, para prevenir el ciberbullying que se presentaba en Facebook en los estudiantes de grados sexto y séptimo, se encontró que no existía una sistematización de las conductas que constituían el ciberbullying; tampoco qué conductas se consideraban como infracciones a la ley ni qué tratamiento se les debía dar tanto a los implicados como a las víctimas en la legislación colombiana a nivel administrativo, preventivo y sancionatorio. 
De acuerdo con lo anterior, es necesario determinar si existe la regulación legal para enfrentar el ciberbullying en Colombia y cómo este se regula en el derecho comparado. Así mismo, es necesario establecer si mediante la socialización de normas administrativas y jurídicas en las instituciones educativas se puede prevenir el ciberbullying.

Es de anotar que no existe una ruta de acción para estudiantes menores y mayores de catorce años en las instituciones escolares frente al ciberbullying, ya que existen lagunas jurídicas para castigar este tipo de conductas, pues desde el punto de vista jurídico no hay leyes específicas para la violencia virtual que permitan establecer cómo regular este tipo de comportamientos; cuestión que es aprovechada por los agresores, quienes normalmente se escudan en el anonimato $y$ en la poca seguridad que existe en Internet.

De acuerdo con lo anterior surge la siguiente formulación del problema: ¿cómo proponer una ruta de actuación frente a los casos de ciberbullying (en adelante, $C B$ ) en las instituciones educativas para garantizar el cumplimiento de los Derechos Humanos de los estudiantes? Ante la cual se propone la siguiente hipótesis: un protocolo de actuación con procedimientos disciplinarios puede informar a estudiantes, docentes, padres de familia y a la comunidad en general para prevenir el ciberbullying y dar cumplimiento a los derechos humanos de los estudiantes.

El objetivo general es diseñar un protocolo de actuación con procedimientos disciplinarios para prevenir el ciberbullying en los colegios públicos urbanos de Duitama.

Para dar cumplimiento al objetivo general se presentan los siguientes objetivos específicos: 
- Establecer el significado de ciberbullying y su prevalencia a nivel mundial.

- Determinar qué conductas constituyen ciberbullying y cuáles se catalogan como delito en Colombia.

- Identificar los procedimientos disciplinarios en los colegios públicos urbanos de Duitama en el año 2018.

- Analizar el protocolo de actuación frente al ciberbullying en el derecho comparado a nivel internacional.

- Analizar el protocolo de actuación en los ámbitos civil y penal frente al ciberbullying en el derecho comparado a nivel nacional, teniendo en cuenta la Ley de infancia y adolescencia (Ley 1098 del 2006), el código penal (Ley 599 del 2000) y el código civil (Ley 57 de 1887).

- Diseñar y socializar una cartilla con el protocolo de actuación con procedimientos administrativos y penales para prevenir el ciberbullying en colegios públicos urbanos de Duitama (Boyacá).

Este trabajo se justifica ya que la UnESCo privilegió las perspectivas de una cultura de paz en las instituciones educativas y definió que esta es el eje y la pedagogía fundamental para el siglo xxi (IIDH, 2014). Así mismo, Delors (1996) sostiene que la educación descansa sobre cuatro pilares: aprender a vivir juntos, aprender a conocer, aprender a hacer y aprender a ser.

Frente a los numerosos desafíos del porvenir, la educación constituye un instrumento indispensable para que la humanidad pueda progresar hacia los ideales de paz, libertad y justicia social. La Comisión desea por tanto afirmar su convicción respecto a la función esencial de la educación 
en el desarrollo continuo de la persona y de las sociedades, al servicio de un desarrollo humano más armonioso, más genuino, para hacer retroceder la pobreza, la exclusión, las incomprensiones, las opresiones, las guerra. (Delors, 1996)

En cuanto a los avances, se estableció el significado de ciberbullying y su prevalencia a nivel mundial y se determinaron las conductas que lo constituyen. Actualmente se están identificando los procedimientos disciplinarios de los colegios y se avanza en los demás objetivos específicos.

\section{Metodología}

\subsection{Tipo de estudio y enfoque}

El tipo de estudio de este trabajo es analítico-descriptivo y su enfoque es sociojurídico ya que se basa en la observación del fenómeno del ciberbullying y lleva a cabo un análisis de cómo la legislación colombiana y las instituciones educativas lo enfrentan para luego, mediante el derecho comparado, establecer un protocolo de actuación para prevenir y actuar frente a él, teniendo siempre en cuenta los derechos humanos.

\subsection{Duitama}

La zona de estudio está ubicada en la ciudad de Duitama, departamento de Boyacá, a 52 kilómetros de la ciudad de Tunja y a 180 kilómetros de la capital de la República. Duitama está ubicada sobre el altiplano cundiboyacense, a una altura de 1600 m.s.n.m. Presenta terreno ondulado y plano, cuenta con zonas ubicadas en piso térmico páramo, sobre los 3200 m.s.n.m. Colinda por el norte con el departamento de Santander, por el oriente con el municipio de Santa Rosa de Viterbo, por el sur con Tibasosa y por el occidente con 
el municipio de Paipa. Tiene una población aproximada de 120000 habitantes. Los renglones económicos predominantes son la industria y el trasporte y ya en una menor escala la agricultura y la ganadería. El servicio público educativo es ofrecido en los niveles preescolar, básico primario, básico secundario y media por instituciones educativas de carácter oficial y privado, tanto en el sector rural como en el urbano. Para el año 2017, en Duitama estaban registradas 14 instituciones educativas oficiales y 52 privadas que ofrecen el nivel preescolar, básica primaria, básica secundaria y media. Para el año 2017, el índice de calidad de la Secretaría de Educación de Duitama, identificado desde el Ministerio de Educación Nacional (MEN), se encuentra en el cuarto cuadrante, es decir, que las acciones encaminadas a su mejoramiento en el eje de calidad la ubican entre las secretarías con mejores resultados a nivel nacional (Secretaría de Educación de Duitama, 2018).

\subsection{Población y muestra}

Duitama cuenta con nueve colegios en el área urbana que se mencionan a continuación:

1. Instituto Técnico Nueva Familia

2. Institución Educativa San Luis

3. Instituto Técnico Industrial Rafael Reyes

4. Instituto Técnico Santo Tomás de Aquino

5. Colegio Boyacá de Duitama

6. Colegio Nacionalizado La Presentación

7. Colegio Técnico Municipal Francisco de Paula Santander

8. Colegio Técnico Municipal Simón Bolívar

9. Colegio Guillermo León Valencia 
La muestra de este estudio se hizo con la población universo de estos nueve colegios.

\subsection{Instrumentos}

Entrevista a rectores, coordinadores o psicólogos de las nueve instituciones educativas públicas urbanas de la ciudad de Duitama.

\section{Avances, resultados, discusión}

\subsection{Significado de ciberbullying y su prevalencia a nivel mundial}

Para empezar, es necesario tener claro el concepto de ciberbullying teniendo en cuenta varios autores, ya que no existe una definición única. El ciberbullying es un neologismo del idioma inglés cuyos sinónimos son: cibermatoneo, ciberacoso, ciberabuso, cibermatonaje, cibermatoneo, abuso online, matoneo online, matonaje online, abuso virtual y matonaje virtual. A continuación se presentan diferentes definiciones:

El ciberbullying en el ambiente virtual [es aquel] donde el autor utiliza las herramientas de la tecnología de la información y la comunicación, en especial internet y el celular, para maltratar a sus compañeros. (Fante, 2012)

Agresión intencional, por parte de un grupo o un individuo, usando formas electrónicas de contacto, repetidas veces, a una víctima que no puede defenderse fácilmente por sí misma. (Smith, 2006)

De acuerdo con la Sentencia T-713 del 2010, se trata de una conducta realizada por una persona menor de edad, la cual entre otros comportamientos molesta, amenaza, hostiga, 
humilla a otra igual menor valiéndose de correos electrónicos, mensajes de texto u otros similares. Implica una intimidación a través de mensajes de correo electrónico, servicios de mensajería instantánea, sitios web o imágenes enviadas a los teléfonos celulares, entre otras formas. Se caracteriza porque (1) se puede desplegar desde al anonimato, lo cual, a su vez; (2) genera que los victimarios lleguen a tener comportamientos que tal vez no tendrían si las intimidaciones fueran en contextos de confrontación personal; (3) los medios para generarlo están al alcance en cualquier momento gracias a las facilidades de acceso de los medios electrónicos; (4) la víctima tiene temor de denunciarlo ante eventuales represalias del victimario o porque se le restrinja el uso de su computador o celular y; (5) el número de espectadores que puede conocer el contenido de los mensajes intimidatorios es alto, dada la demanda de usuarios de internet (Violence Prevencion Works, 2016).

Según Standler (2002), el ciberacoso es definido como las amenazas, el hostigamiento, las humillaciones y cualquier otra forma de desagrados realizada por un individuo y dirigida a otro sujeto, por medio de tecnologías telemagnéticas de comunicación como lo son el internet, la telefonía móvil, las videoconsolas online, entre otros.

El acoso escolar a través de correos electrónicos, mensajes instantáneos — MSM, Messenger-, salas de chat, páginas web o a través de mensajes o imágenes digitales enviadas a un teléfono móvil (Kowalaski, 2010). Por su parte, Menesini, Nocentini y Calussi (2011), en un estudio, construyen la definición de ciberbullying a través de diez conductas: 1) envío de mensajes de texto ofensivos; 2) envío de fotos o vídeos de escenas violentas a través del teléfono móvil; 3) envío de fotos o vídeos de escenas íntimas a través del 
teléfono móvil; 4) realizar llamadas de teléfono en las que, cuando la víctima responde, se guarda silencio o se gastan bromas; 5) envío de email agresivos; 6) insultar en sitios web; 7) insultar en aplicaciones de mensajería instantánea; 8) insultar en salas de chats; 9) insultar en blogs; y 10) subir fotos o dibujos desagradables en sitios web.

Mora-Merchán et al. (2010, p. 193) indican que las siguientes acciones conforman el ciberbullying: 1) provocación incendiaria, en la que se incluyen peleas o discusiones encendidas online por medio de mensajes electrónicos; 2) hostigamiento, que es el envío repetido de mensajes a una víctima que no los desea recibir; 3) denigración, consistente en insultar a alguien, mentir o difundir rumores sobre una persona para dañar su imagen o estatus social; 4) suplantación de la personalidad de alguien, a través de la utilización de las cuentas de acceso o el móvil de la víctima, hacerse pasar por ella para cometer actos inapropiados, hacerla quedar mal ante los demás, dañar su reputación u originar conflictos con sus conocidos; 5) violación de la intimidad o juego sucio, o difundir información o imágenes de la víctima sin su consentimiento, en ocasiones, incluso los propios agresores pueden engañar a las víctimas para que ellas mismas envíen la información o fotografías; 6) exclusión, o aislar a alguien de modo intencional de un grupo online; 7) ciberacoso propiamente dicho, con el envío repetido de mensajes amenazantes o intimidatorios, en cualquier momento y en cualquier actividad mediante el uso de las nuevas tecnologías.

De acuerdo con lo anterior, se puede establecer que el ciberbullying consiste en el uso de las TIC para amenazar físicamente, asediar verbalmente o excluir socialmente a un individuo o un grupo. Es un tipo de agresión psicológica en la que se usan teléfonos celulares, internet y juegos en línea para 
enviar mensajes, correos, o videos con el fin de molestar e insultar a otra persona. Este acoso incluye el uso de correos electrónicos, mensajes instantáneos, mensajes de texto e imágenes digitales enviados a través de teléfonos móviles, páginas web, bitácoras webs (blogs), salas de chat o coloquios online, y demás tecnologías asociadas a la comunicación digital.

\subsection{Estudios llevados a cabo}

Los países anglosajones fueron los primeros en desarrollar estudios sobre ciberbullying, como señalan Mora-Merchán et al. (2010). En la tabla 1 se resume la prevalencia del $c i-$ berbullying a nivel mundial.

Tabla 1. Prevalencia del ciberbullying a nivel mundial

\begin{tabular}{|c|l|l|}
\hline Año & \multicolumn{1}{|c|}{ País } & \multicolumn{1}{c|}{ Estudio } \\
\hline 2004 & $\begin{array}{l}\text { Estados } \\
\text { Unidos }\end{array}$ & $\begin{array}{l}\text { Ybarray Mitchell,2004.12\% los jóvenes encuestados que dicen } \\
\text { haber agredido utilizando medios electrónico }\end{array}$ \\
\hline 2006 & $\begin{array}{l}\text { Reino } \\
\text { Unido }\end{array}$ & $\begin{array}{l}\text { Smith et al.,2008. Indican porcentajes de prevalencia de jóvenes } \\
\text { que dicen ser victimizados online (22\%) y de manera frecuente } \\
\text { online (13\%).Un trabajo más de ese país indica que el porcentaje } \\
\text { de jóvenes agresores es del 5\%. }\end{array}$ \\
\hline 2007 & España & $\begin{array}{l}\text { Defensor del Pueblo, 2007. E1 5,5\% de los estudiantes } \\
\text { encuestados ha utilizado los medios electrónicos para acosar } \\
\text { a sus compañeros en alguna ocasión y lo ha hecho de manera } \\
\text { frecuente en el 0,4\% de los casos analizados. }\end{array}$ \\
\hline 2007 & $\begin{array}{l}\text { Estados } \\
\text { Unidos }\end{array}$ & $\begin{array}{l}\text { Williams y Guerra, 2007.12\% de alumnos que dice ser agresor } \\
\text { a través de Internet en 2005. }\end{array}$ \\
\hline 2008 & $\begin{array}{l}\text { Estados } \\
\text { Unidos }\end{array}$ & $\begin{array}{l}\text { Raskauskas y Stoltz, 2007. Concluyen que existe un 49\% } \\
\text { de jóvenes que afirman ser victimizados online y un 21\% de } \\
\text { adolescentes que dicen haber agredido a través de medios } \\
\text { telemáticos en alguna ocasión. }\end{array}$ \\
\hline Unidos & $\begin{array}{l}\text { Hindujay Patchin,2008. El18\% de chicos y el 15,6\% de chicas } \\
\text { están inmersos en esta problemática. }\end{array}$ \\
\hline Holanda & $\begin{array}{l}\text { Dehue, Bolman y Völlink, 2008. Concluyen con un 16\% de } \\
\text { prevalencia de agresión online. }\end{array}$ \\
\hline
\end{tabular}




\begin{tabular}{|c|c|c|}
\hline Año & País & Estudio \\
\hline 2009 & Austria & $\begin{array}{l}\text { Gradinger et al., } 2009.5,3 \% \text { de jóvenes dice ser agresores y un } \\
7,1 \% \text { contesta que es víctima online. }\end{array}$ \\
\hline 2009 & Alemania & $\begin{array}{l}\text { Schultzc-Krumbholzy Scheithaner, 2009.16,9\% de estudiantes } \\
\text { que manifiesta ser agresores y un 15,5\% de la muestra encuestada } \\
\text { que indica ser víctima. }\end{array}$ \\
\hline 2009 & España & $\begin{array}{l}\text { Avilés, 2009. Al analizar los resultados de ciberbullying a lo largo } \\
\text { de dos meses encuentra que las víctimas a través del teléfono } \\
\text { móvil suponen un } 4,5 \% \text { de los jóvenes encuestados y, a través } \\
\text { de Internet, un } 4,7 \% \text { de los mismos; los que dicen ser agresores } \\
\text { utilizando el teléfono móvil son un } 3 \% \text { y con la utilización de } \\
\text { Internet, un } 4,4 \% \text { de los estudiantes que forman parte de la } \\
\text { muestra del estudio. }\end{array}$ \\
\hline 2010 & España & $\begin{array}{l}\text { Mora-Merchán et al., 2010. Un 7,4\% de los jóvenes encuestados } \\
\text { en este trabajo dice ser agresor online; un 10,8\% afirma ser víctima } \\
\text { online, y un 8,4\% de ellos presenta un perfil mixto agresión- } \\
\text { victimización. Los afectados de forma frecuente son un 1,7\% en } \\
\text { el caso de agresores; un 1,5\% en el caso de víctimas, y un 0,6\% } \\
\text { en el perfil mixto de agresores víctimas. }\end{array}$ \\
\hline 2010 & España & $\begin{array}{l}\text { Buelga, Cava y Musitu, 2010. Sobre victimización a través de } \\
\text { teléfono móvil e Internet halla que el } 24,6 \% \text { de los adolescentes } \\
\text { dice haber sido acosado por el móvil y el } 29 \% \text {, por Internet. }\end{array}$ \\
\hline 2010 & Turquía & $\begin{array}{l}\text { Dilmaç y Aydogan, 2010. Un 56,2\% de los jóvenes preguntados } \\
\text { dice sentirse víctima de las conductas de ciberbullying; un 19,6\% } \\
\text { afirma haber agredido online y, como dato adicional, un } 44,5 \% \\
\text { ha ocultado alguna vez su identidad en Internet para cometer } \\
\text { una agresión online. }\end{array}$ \\
\hline 2010 & China & $\begin{array}{l}\text { Calvete et al., 2010. El índice de prevalencia media de las } \\
\text { conductas agresivas online es del } 7 \% \text {. }\end{array}$ \\
\hline 2011 & España & $\begin{array}{l}\text { Álvarez-García, Núñez, Álvarez, Dobarro, Rodríguez y } \\
\text { González-Castro, 2011. Encontraron entre el 35,4\% y el 51,9\% } \\
\text { de adolescentes que habían sido testigos de estas conductas en } \\
\text { educación secundaria. }\end{array}$ \\
\hline 2011 & Bélgica & $\begin{array}{l}\text { Walrave y Heirman, 2011. Hallan un } 34,2 \% \text { de jóvenes que } \\
\text { afirman ser víctimas ( } 2,4 \% \text { de ellos dice que era de manera } \\
\text { frecuente); y un } 21,2 \% \text { de estudiantes que afirman haber agredido } \\
\text { alguna vez (un } 2 \% \text { de ellos afirma haberlo hecho de manera } \\
\text { frecuente). }\end{array}$ \\
\hline
\end{tabular}

Continúa 


\begin{tabular}{|c|c|c|}
\hline Año & País & Estudio \\
\hline 2011 & Italia & $\begin{array}{l}\text { Menesini et al., 2011. Estos autores hallan entre un } 40-50 \% \text { de } \\
\text { estudiantes que dice haber agredido alguna vez a sus compañeros } \\
\text { de manera online. }\end{array}$ \\
\hline 2011 & Serbia & $\begin{array}{l}\text { Popovic-Citic, Djuric y Cvetkovic, 2011. Encuentran índices } \\
\text { de agresión de un } 11,6 \% \text { de jóvenes implicados en casos de } \\
\text { acoso online; un } 10,1 \% \text { en casos de denigración y un } 8,5 \% \text { en } \\
\text { casos de exclusión. }\end{array}$ \\
\hline 2012 & Japón & $\begin{array}{l}\text { Oguda, Hamada,Yamawaki, Honjoy Kaneko, 2012. Encuentran } \\
\text { un porcentaje de } 1,1 \% \text { de jóvenes que dicen ser ciberagresores; un } \\
1,2 \% \text { de encuestados que afirman ser cibervíctimas, y un } 0,5 \% \\
\text { que manifiestan haber agredido y haber sido agredidos de forma } \\
\text { online. Asimismo, su principal conclusión es que el ciberacoso está } \\
\text { relacionado con menores puntuaciones en conducta prosocial. }\end{array}$ \\
\hline 2012 & Bélgica & $\begin{array}{l}\text { Lembrecht, 2012. Un 9,2\% de su muestra dice haber agredido } \\
\text { en alguna ocasión en el ámbito de ciberbullying. }\end{array}$ \\
\hline 2012 & Inglaterra & $\begin{array}{l}\text { Monks et al., 2012. Se halla un 20,5\% de alumnos que dicen } \\
\text { sentirse víctimas online frente a un } 5 \% \text { de estudiantes que afirman } \\
\text { ser agresores en el ciberespacio. }\end{array}$ \\
\hline 2012 & Australia & $\begin{array}{l}\text { Hemphill et al., 2012. 14,7\% de los jóvenes dicen ser agresores } \\
\text { en el ciberespacio. }\end{array}$ \\
\hline 2012 & España & $\begin{array}{l}\text { Bartrina, 2012. En el que se analizan sentencias en materia de } \\
\text { justicia de menores en Cataluña sobre aspectos relacionados } \\
\text { con el uso de las nuevas tecnologías y el ciberbullying; llega a la } \\
\text { conclusión de que la incidencia es baja, en torno al 10,9\% de } \\
\text { casos que llega a la Fiscalía de Menores. }\end{array}$ \\
\hline 2013 & Canadá & $\begin{array}{l}\text { Cappadocia y Craig, 2013. Índices de agresión de entre el } 5 \% \text { y } \\
\text { el } 35 \% \text { de jóvenes encuestados, y de victimización entre el } 20 \% \\
\text { y el } 40 \% \text { de adolescentes; así como índices mixtos, de agresión- } \\
\text { victimización de entre el } 3 \% \text { y el } 14 \% \text { de la muestra analizada. }\end{array}$ \\
\hline 2013 & Grecia & $\begin{array}{l}\text { Lazuras, Barkuukis, Ourda Txorbatzoudis, } 2013.32,4 \% \text { de } \\
\text { víctimas y } 12,5 \% \text { de estudiantes que son agresores de ciberbullying. }\end{array}$ \\
\hline 2013 & Suecia & $\begin{array}{l}\text { Slonje y Smith, 2008. 17,6\% de jóvenes han manifestado ser } \\
\text { víctimas online y } 11,9 \% \text { ha dicho ser agresor online también. }\end{array}$ \\
\hline 2013 & Finlandia & $\begin{array}{l}\text { Elledge, Williford, Boulton, DePaolis, Luttle Salmivalli, } 2013 \text {. } \\
\text { El índice de agresión se sitúa en el } 4 \% \text { de los sujetos encuestados } \\
\text { a través del programa Kiva Antibullying. }\end{array}$ \\
\hline
\end{tabular}

Fuente: recopilación realizada por las autoras en 2018. 
De acuerdo con la tabla anterior se establece que en el periodo de 2004 a 2010 en países como Estados Unidos, España, Holanda, Austria y Alemania el $C B$ aumentó del 12 al 25\%. Entre los años 2011 y 2013, en países como España, Bélgica, Italia, Inglaterra y Canadá, el porcentaje de víctimas de $C B$ aumentó y alcanzó un $35 \%$.

A nivel nacional, Clemente (2017), en su estudio Aproximación a un estudio comparado: Latinoamérica y España, estableció que el $C B$ en Colombia se sitúa en tasas del 40 al $70 \%$ durante los últimos diez años; sin embargo, para Herrera et al. (2018), en el estudio Bullying y cyberbullying en Colombia; concurrencia en adolescentes escolarizado, este índice está en un 18,7\%.

Para el caso objeto de estudio, de acuerdo con Pinzón (2017), en la investigación Ciberbullying en estudiantes de los grados $6^{\circ}, 9^{\circ}$ y $11^{\circ}$ de colegios públicos de la ciudad de Duitama, la prevalencia se ubica para las víctimas en un 7,1\%, y para agresores, el 8,8\%.

\subsection{Determinar qué conductas constituyen ciberbullying y cuáles pueden catalogarse como delito en Colombia} Dentro de las conductas que constituyen $C B$ están los insultos, el hostigamiento, la denigración, las amenazas, las coacciones, las lesiones a la dignidad, que se hacen a través de medios electrónicos. En la tabla 2 se presenta la responsabilidad de tipo penal del $C B$ en Colombia. 
Tabla 2. Responsabilidad de tipo penal según el código penal

\begin{tabular}{|l|l|}
\hline Art.220 & Injuria \\
\hline Art.221 & Calumnia \\
\hline Art.269 A & Acceso abusivo a un sistema informático \\
\hline Art.269 F & Violación de datos personales \\
\hline Art.182 & Constreñimiento ilegal (obligar a otro) \\
\hline Art.210 A & Acoso sexual \\
\hline
\end{tabular}

Fuente: recopilación realizada por las autoras, 2018.

En cuanto a la responsabilidad de tipo civil, según el código civil se tiene:

Artículo 2346. Responsabilidad por daños causados por dementes e impúberes. Los menores de diez años no son capaces de cometer delito o culpa, pero los daños por ellos causados serán responsables las personas a cuyo cargo estén dichos menores. Delito de homicidio o asesinato, Delito de inducción al suicidio, Delitos de lesiones, Delitos de amenazas o coacciones, Delito de acoso u hostigamiento, Delito contra la integridad moral, Delito de posesión o acceso a sabiendas a material de pornografía infantil, Delitos de calumnia e injurias.

\subsection{Normatividad relacionada con el ciberbullying a nivel nacional teniendo en cuenta la Ley de Infancia y Adolescencia, el código penal y el código civil}

Véanse a continuación las tablas 3 y 4. 


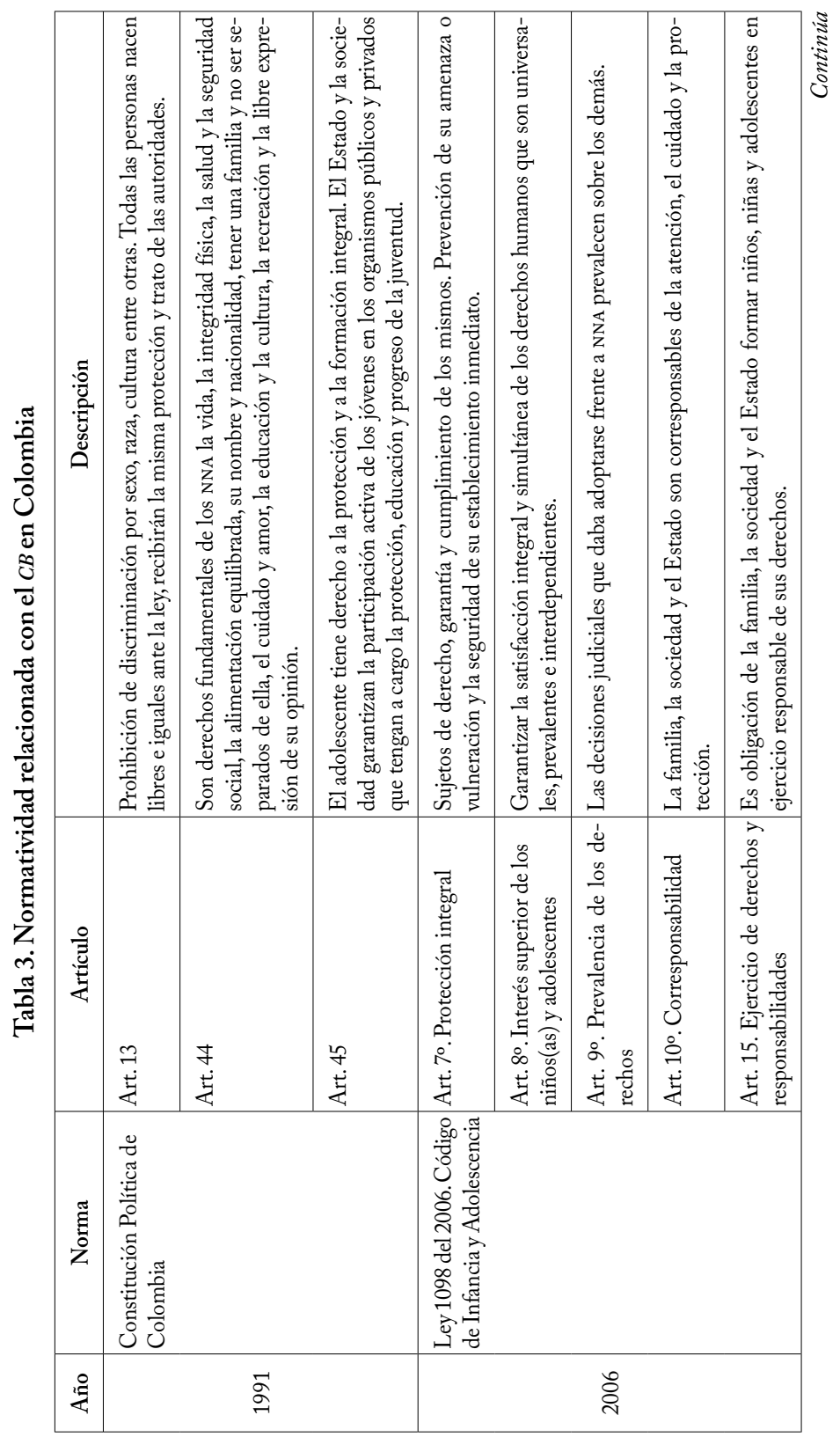




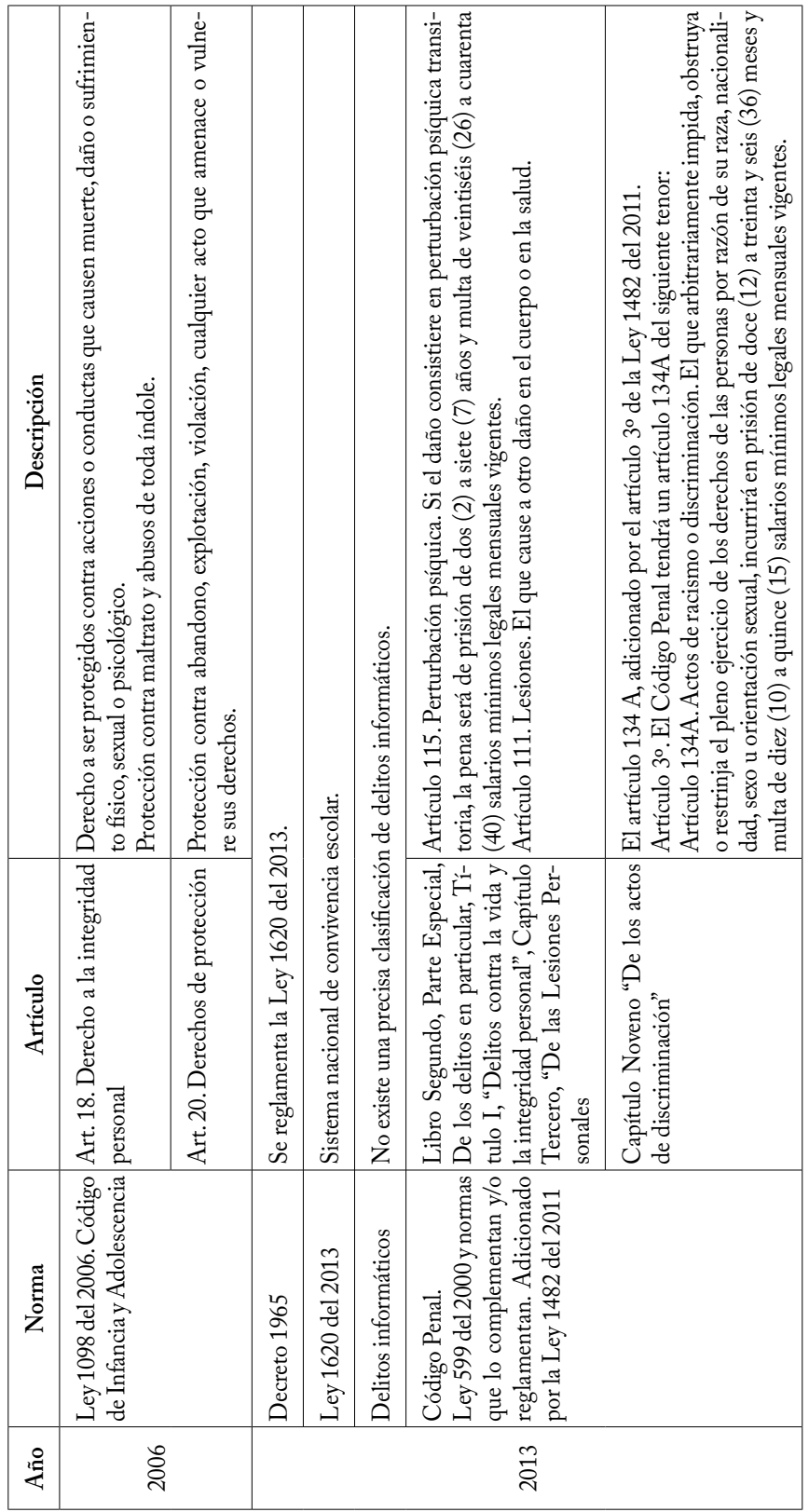




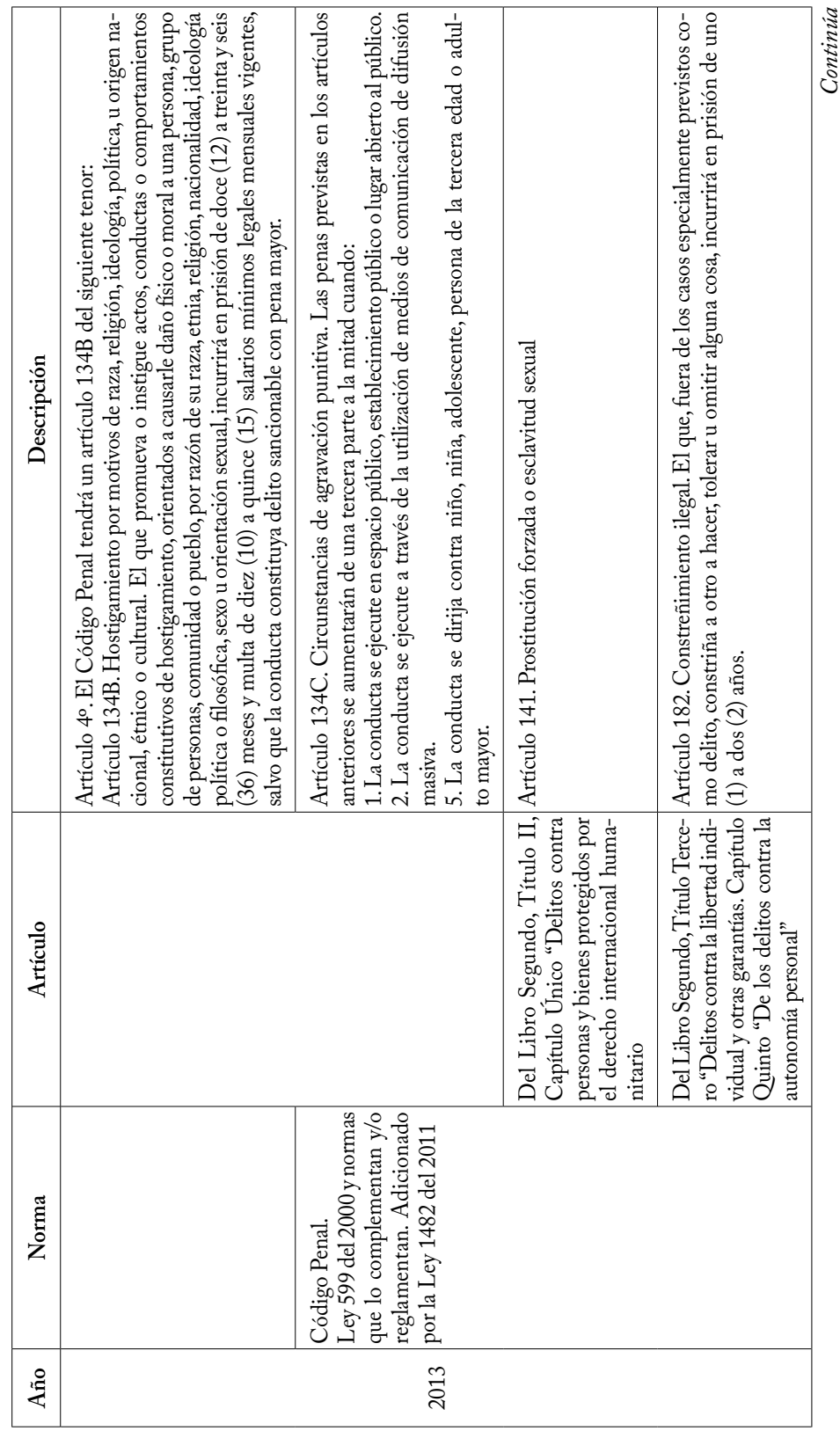




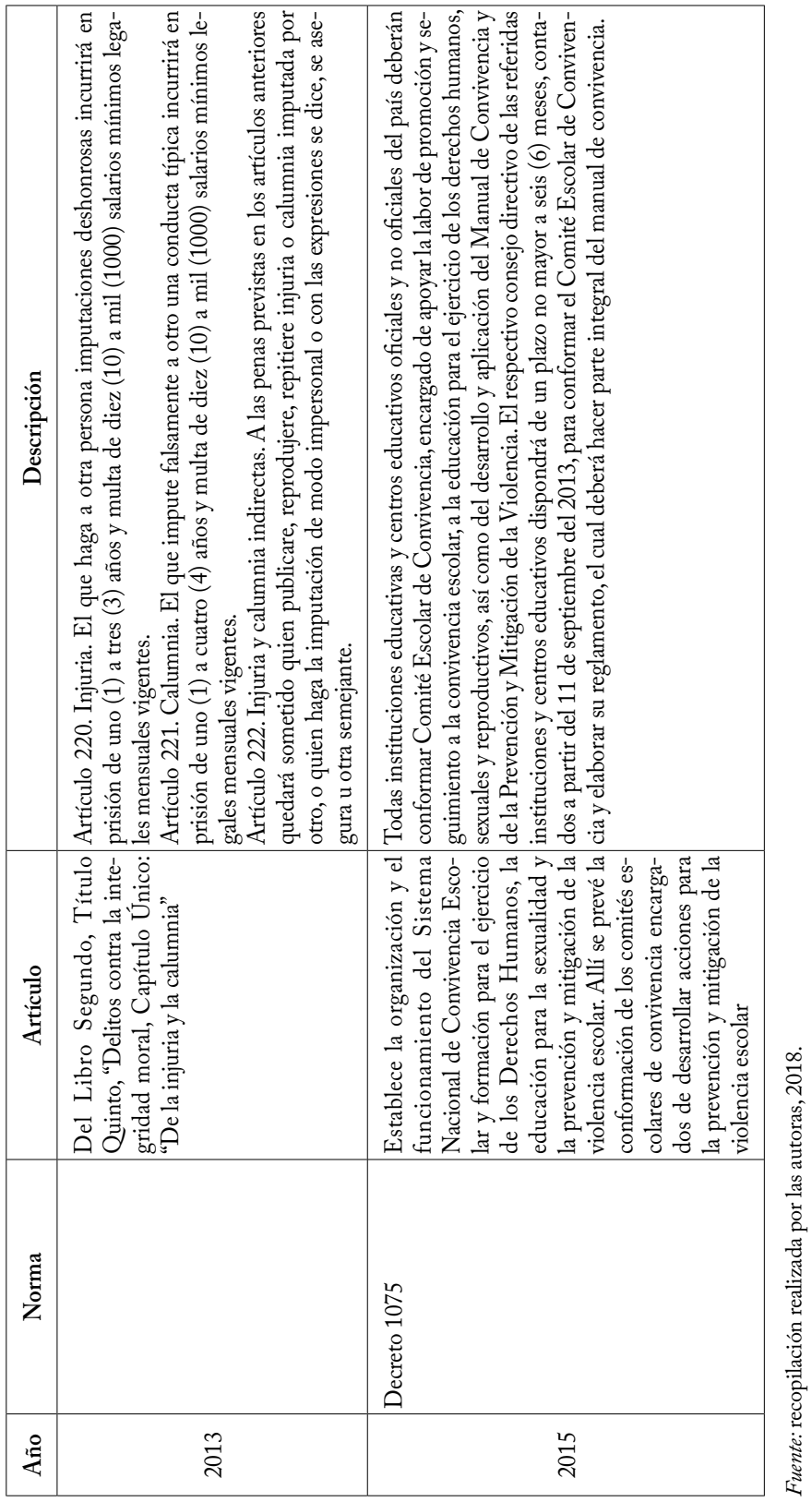




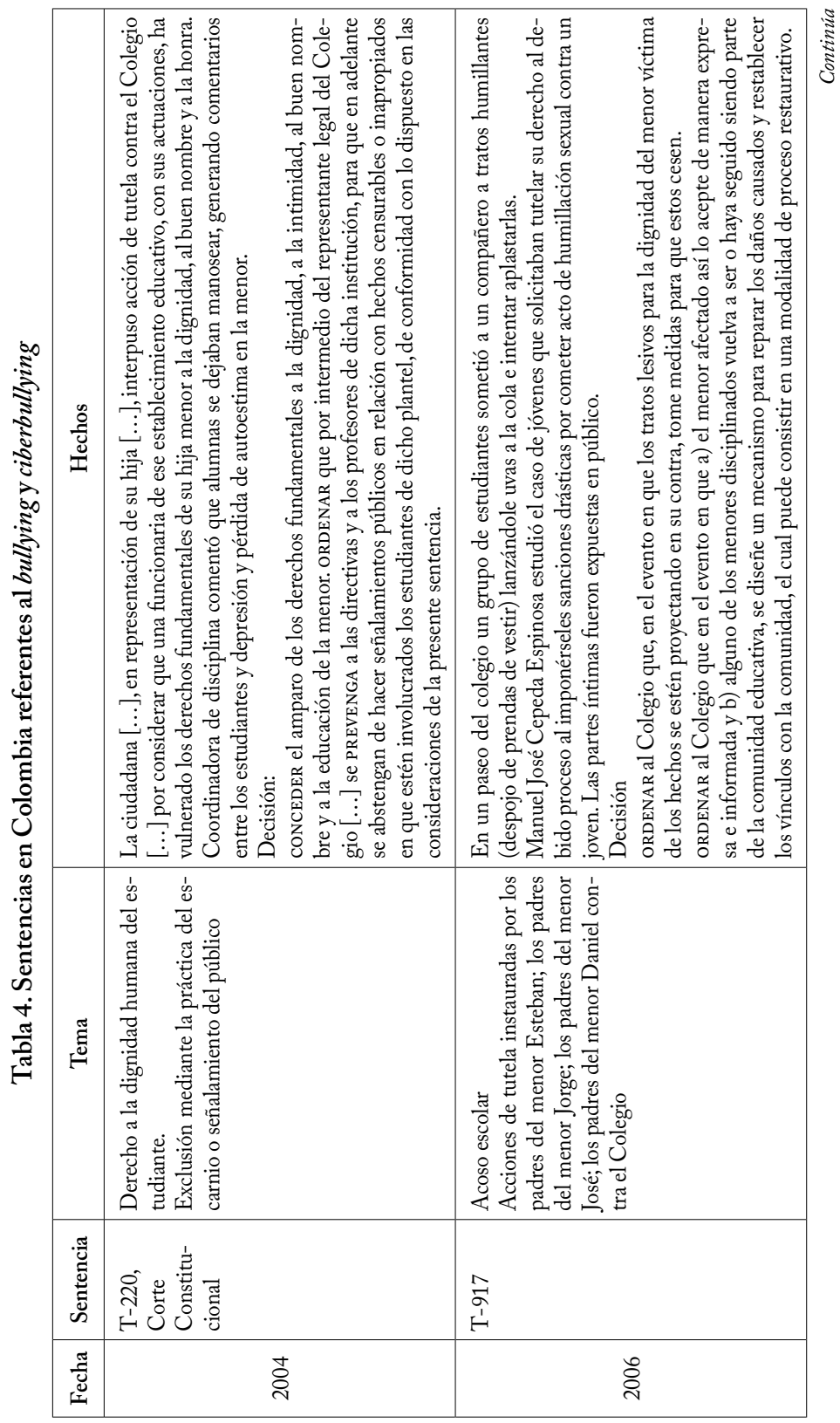




\begin{tabular}{|c|c|c|}
\hline & 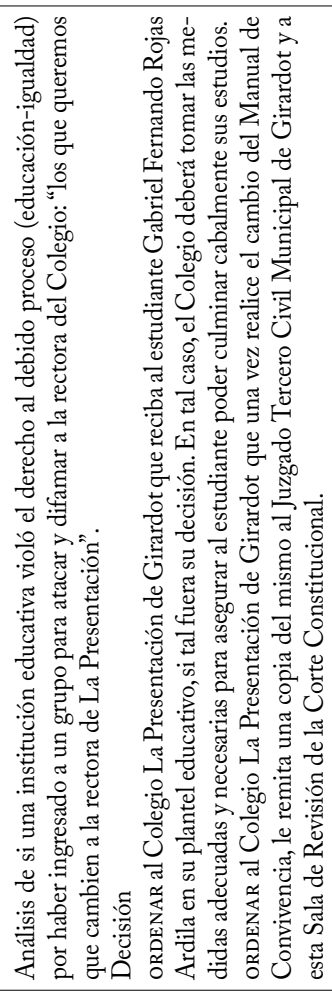 & 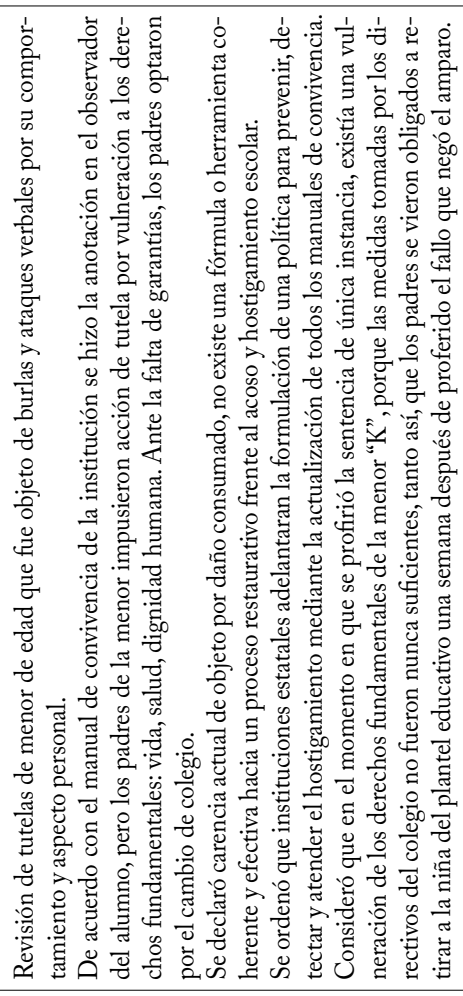 \\
\hline 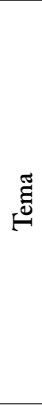 & 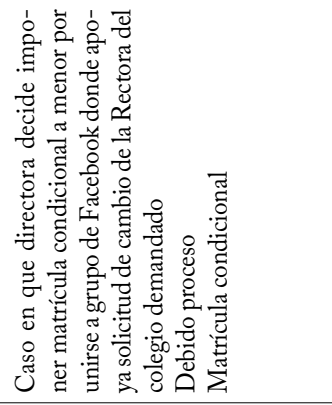 & 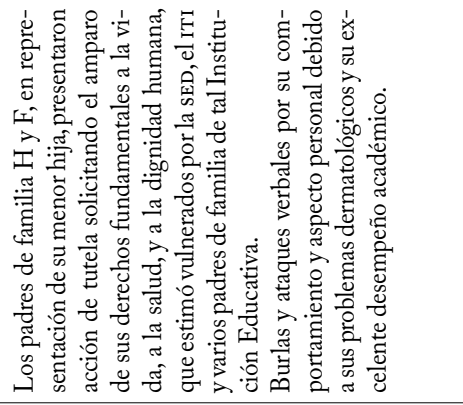 \\
\hline . & 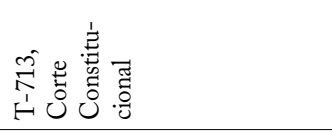 & 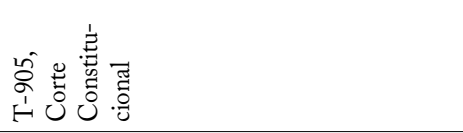 \\
\hline $\begin{array}{l}\frac{\pi}{\tilde{J}} \\
\text {. }\end{array}$ & $\vec{v}$ & \\
\hline
\end{tabular}




\begin{tabular}{|c|c|c|}
\hline & 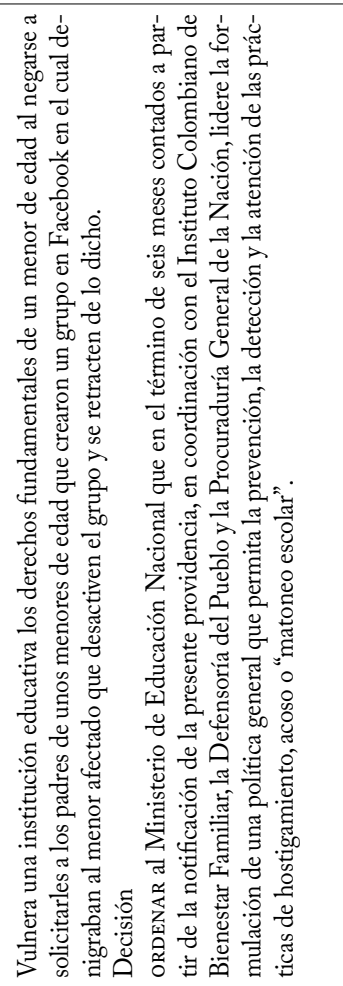 & 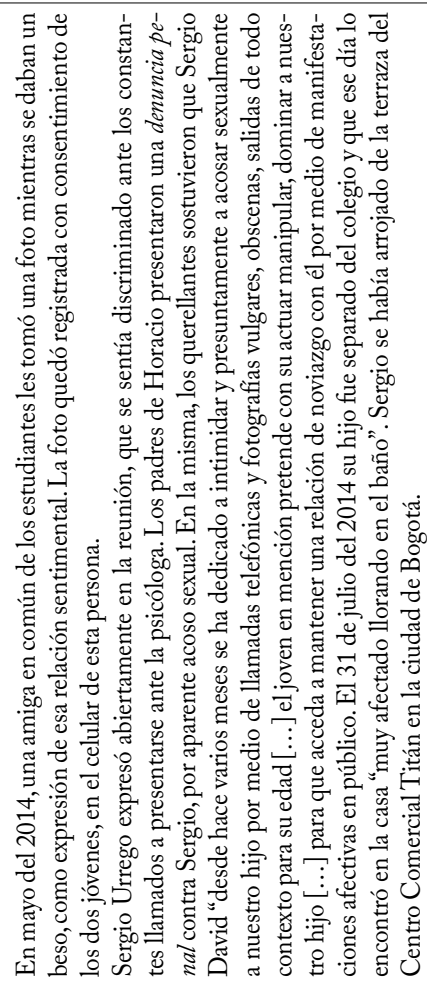 \\
\hline ⿷匚ّ & 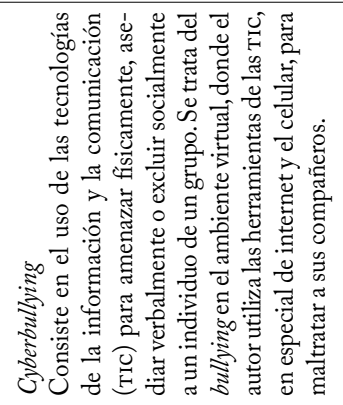 & 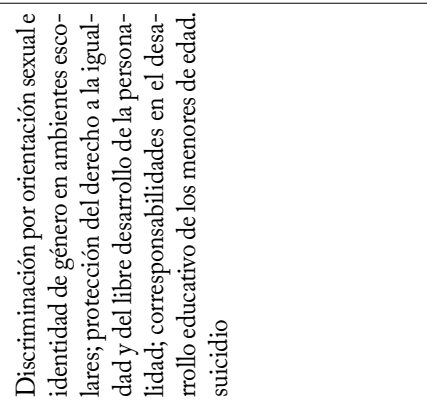 \\
\hline & 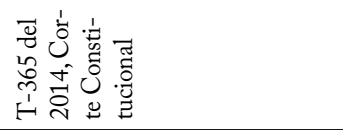 & 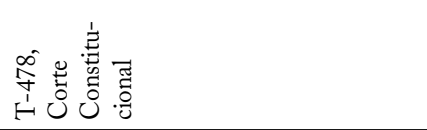 \\
\hline 宽 & ¿ి & ల \\
\hline
\end{tabular}




\begin{tabular}{|c|c|c|}
\hline & 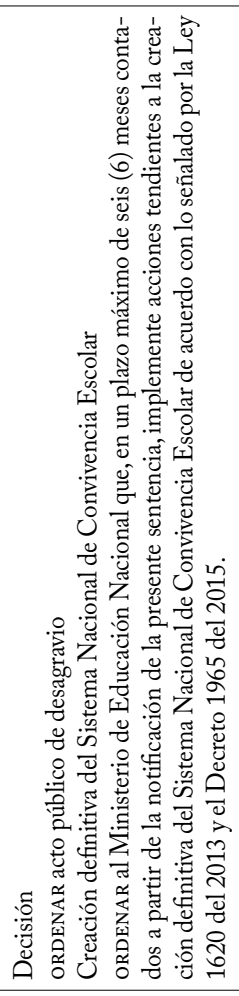 & 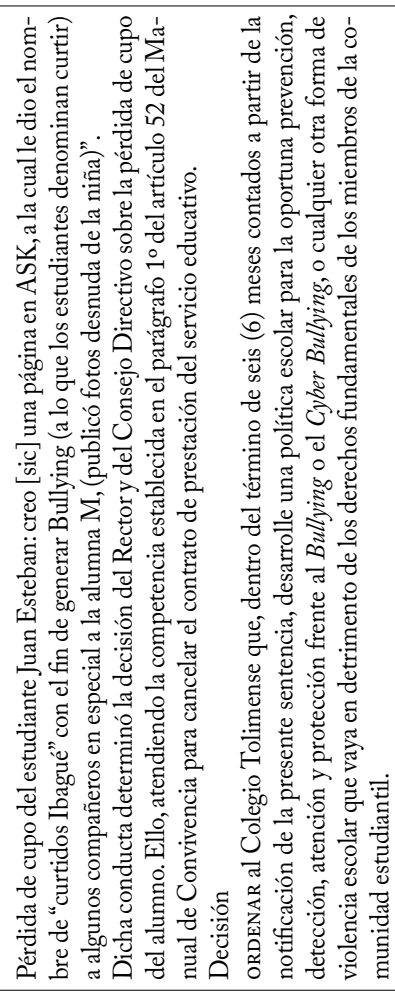 \\
\hline 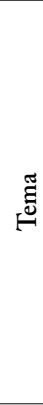 & & 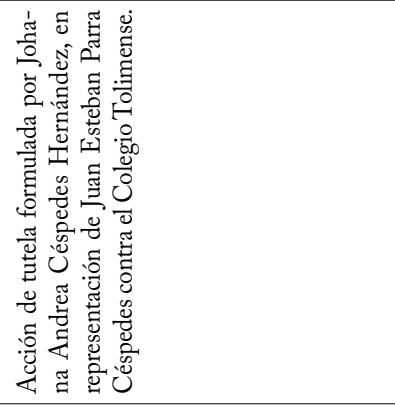 \\
\hline 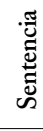 & & 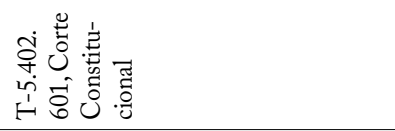 \\
\hline 胥 & & $\approx$ \\
\hline
\end{tabular}




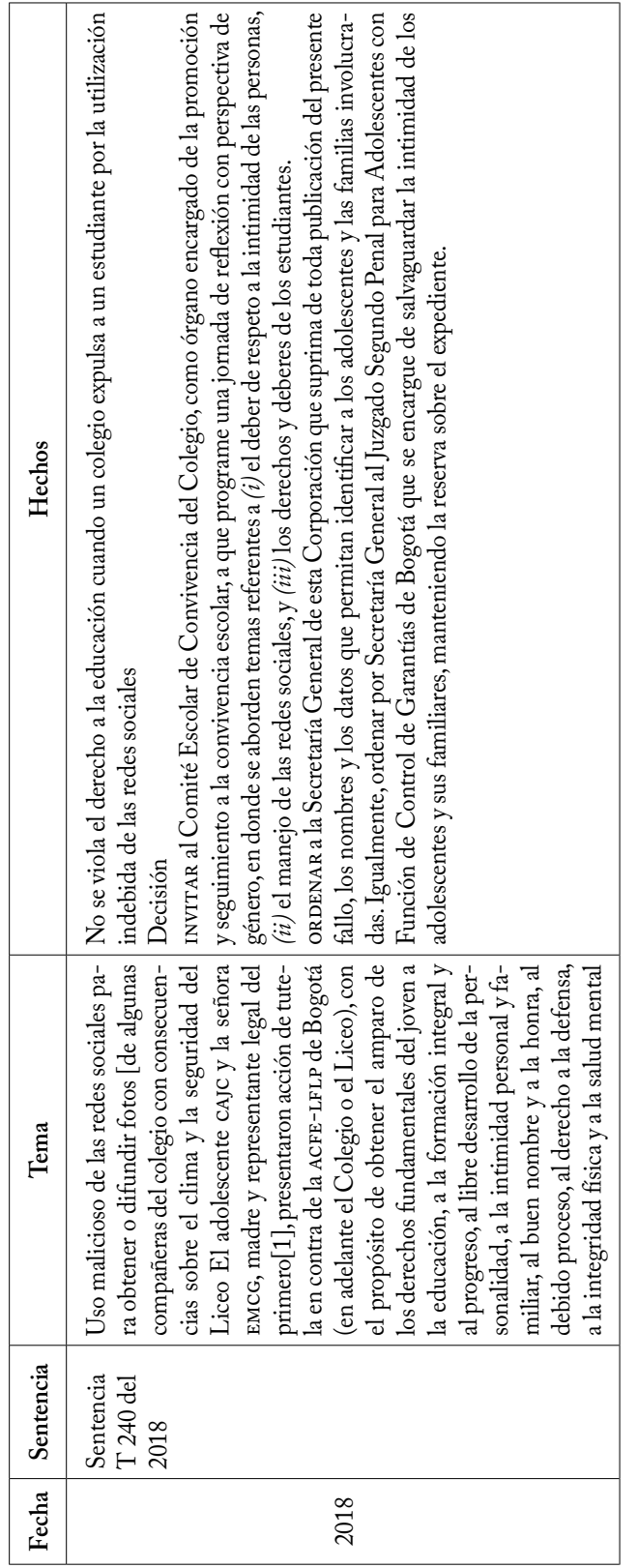

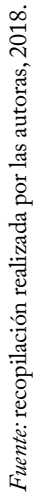


Recopilando, la Corte Constitucional ha indicado que pese a la amplia potestad que tienen los planteles educativos para ejercer acciones disciplinarias sobre sus estudiantes, las investigaciones de este rigor que promuevan sobre ellos deben estar precedidas de un procedimiento que prevea la posibilidad de ejercer el derecho a la defensa, presentar y controvertir pruebas, entre otras. Para tal fin, los manuales de convivencia adoptados por los centros educativos deben propiciar estas condiciones en aras de garantizar la protección del derecho fundamental al debido proceso.

\subsection{Procedimientos disciplinarios en colegios y diseño de cartilla}

La identificación de procedimientos disciplinarios en los colegios urbanos de Duitama y el diseño y socialización de la cartilla con el protocolo de actuación están en proceso de desarrollo.

\section{Conclusiones}

Para garantizar los derechos humanos, la democracia y el uso de nuevas tecnologías es necesario contar con un protocolo de actuación: procedimientos disciplinarios para los colegios, en donde se establezca la ruta a seguir a nivel preventivo (Código de Infancia y Adolescencia), administrativo (manuales de convivencia) y sancionatorio (códigos civil y penal), a través de medidas restaurativas o sancionatorias.

Existen múltiples definiciones de $C B$; sin embargo, en este estudio se puede establecer que consiste en el uso de las TIC para amenazar físicamente, asediar verbalmente o excluir socialmente a un individuo o a un grupo. Es un tipo de agresión psicológica en el que se usan teléfonos celulares, internet y juegos en línea para enviar mensajes, correos o 
videos con el fin de molestar e insultar a otra persona. Dentro de las conductas que constituyen $C B$ están los insultos, el hostigamiento, la denigración, las amenazas, las coacciones y las lesiones a la dignidad.

Es difícil establecer una comparación de la prevalencia del $C B$ a nivel internacional, nacional y local debido a la diferencia entre muestras, a los diversos instrumentos y a las definiciones que se le da al $C B$; sin embargo, en todos los países se constata una alta prevalencia de este.

Frente al ciberbullying que se encuentra en los colegios se propone un protocolo de actuación para la comunidad en general como elemento transformador para la administración de justicia. De esta manera se pretende contribuir con información y garantizar los derechos humanos de las víctimas y agresores. Se resalta que la comunidad en general no tiene una ruta de acción para enfrentar el $C B$ a nivel civil y penal, motivo por el cual es necesario el protocolo de actuación.

Finalmente, los manuales de convivencia adoptados por los centros educativos deben garantizar la protección del derecho fundamental al debido proceso.

\section{Referencias}

Agatson, P., Limber, S., \& Kowalski, R. (2010). El acoso escolar en la era digital (1. ${ }^{\mathrm{a}}$ ed.). Malden, EE.UU.: Descleé editoriales.

Álvarez-García, D., Núñez, J., Álvarez, L., Dobarro, A. \& Rodríguez, C. (2014). La violencia escolar en los centros de educación secundaria de Asturias desde la perspectiva del alumnado. Educación XXI, 17(2), 337-360.

Avilés, J. (2009). Ciberbullying. Diferencias entre el alumnado de secundaria. Boletín de Psicología, 96, 79-96. 
Bartrina, M.J. (2012). Análisis y abordaje del acoso entre iguales mediante el uso de las nuevas tecnologías. Barcelona: Centro de Estudios Jurídicos y Formación Especializada.

Buelga, S., Cava, M., \& Musitu, G. (2010). Cyberbullying: victimización entre adolescentes a través del teléfono móvil y de Internet. Psicothema, 22(4), 784-789.

Calvete, E., Orue, I., Estévez, A., Villardón, L., \& Padilla, P. (2010). Cyberbullying in adolescents: modalities and agressors' profile. Computers in Human Behaviour, 26, 1128-1135.

Cappadocia, M. C., \& Craig, W. M. (2013). Cyberbullying: prevalence, stability, and risk factors during adolescence. Canadian Journal of School Psychology, 28(2), 171-192.

Clemente, A. (2017). Aproximación a un estudio comparado: Latinoamérica y España. Universidad Internacional de Valencia.

Constitución Política de Colombia (1991).

Defensor del Pueblo (2007). Violencia escolar: el maltrato entre iguales en la educación secundaria obligatoria 1999-2006. Nuevo estudio y actualización del informe 2000. Madrid: Informes, estudios y documentos.

Dehue, F., Bolman, C., \& Völlink, T. (2008). Cyberbullying: youngters experiences and parental perception. Cyberpsychology Behavior, 11(2), 217-223.

Delors, J. (1996). La educación encierra un tesoro. Informe a la UNESCO de la Comisión Internacional sobre Educación para el siglo XXI. París: Ediciones unesco.

Dilmaç, B., \& Aydogan, D. (2010a). Parental attitudes as a predictor of cyber bullying among primari school children. World Academy of Science, Engineering and Technology, 67, 167-171. 
Dilmaç, B., \& Aydogan, D. (2010b). Values as a predictor of ciber-bullying among secondary school students. International Journal of Social Sciences, 5(3), 185-188.

Elledge, L., Williford, A., Boulton, A., DePaolis, T., \& Salmivalli, C. (2013). Individual and contextual predictors of cyberbullying: the influence of children's provictim attitudes and teacher's ability to intervene. Journal of Youth and Adolescence, 42, 698-710.

Fante, C. (2012). Cómo entender y detener el bullying y el cyberbullying en la escuela. 112 preguntas y respuestas clave para profesores y padres. Bogotá: Editorial Magisterio.

Gradinger, P., Strohmeier, D., \& Spiel, C. (2009). Traditional bullying and cyberbullying. Identification of risk groups for adjustment problems. Zeitschrift für Psychologie/Journal of Psychology, 217(4), 205-213.

Hemphill, S., Kotevski, A., Tollit, M., Smith, R., Herrenkohl, T., Toumbourou, J., \& Catalano, R. (2012). Longitudinal predictors of cyber and traditional bullying perpetration in Australian Secondary School students. Journal of Adolescence Health, 51, 59-65.

Herrera-López, M., Romera, E., \& Ortega-Ruiz, R. (2018). Bullying y cyberbullying en Colombia; concurrencia en adolescentes escolarizados. Revista Latinoamericana de Psicologia, 49(3), 161-222.

Hinduja, S., \& Patchin J. W. (2008). Cyberbullying: An exploratory analysis of factors related to offending and victimization. Deviant Behavior, 29, 1-29.

Instituto Interamericano de Derechos Humanos (2014). Prevención del acoso escolar. Bullying y Ciberbullying. Texto autoformativo y multimedia. Gobierno de Australia. Embajada de Australia en México. Programa de Ayuda Directa. Ministerio de Educación Pública de Costa Rica. 
Lazuras, L., Barkoukis, V., Ourda, D., \& Tsorbatzoudis, H. (2013). A process model of cyberbullying in adolescence. Computers in human behaviour, 29, 881-887.

Lembrecht, L. (2012). Digital image bullying among school students in Belgium: an exploration of the characteristics of bullies and their victims. International Journal of Cyber Criminology, 6(2), 968-983.

Menesini, E., Nocentini, A., \& Calussi, P. (2011). The measurement of cyberbullying: dimensional structure and relative item severity and discrimination. Cyberpsichology, behaviour and social networking, 14(5), 267-274.

Monks, C., Robinson, S., \&Worlidge,P.(2012). The emergence of cyberbullying: a survey of primary school pupils' perceptions and experiences. School Psychology International, 33(5), Doi: 10.1177/0143034312445242.

Mora-Merchán, J., Ortega, R., Calmaestra, J., \& Smith, P. (2010). El uso violento de la tecnología: el ciberbullying. En R. Ortega (Ed.), Agresividad injustificada, bullying y violencia escolar (pp. 189-209). Madrid: Alianza Editorial. Oguda, M., Hamada, S., Yamawaki, A., Honjo, S., \& Kaneko, H. (2012). IJıME among Japanese junior high school students - traditional bullying and cyberbullying. Actas del 20 Congreso Mundial de Neuropsiquiatría de la infancia y la adolescencia, Japón.

Declaración Universal de los Derechos Humanos (2017). Recuperado de http://www.un.org/es/universal-declarationhuman-rights/

Pinzón, A. L. (2018). Ciberbullying en estudiantes de los grados $6^{\circ}, 9^{\circ}$ y $11^{\circ}$ de colegios públicos de la ciudad de Duitama. Universidad Pedagógica y Tecnológica de Colombia.

Popović-Ćitić, B., Djurić, S., \& Cvetković, V. (2011). The prevalence of cyberbullying among adolescence: a case 
study of middle schools in Serbia. School Psychology International, 32, 411-424.

Public Safety Canada (2008). School Safety Net (ssm), ¿¿Qué es el cyberbullying?”. Recuperado de http://www.ciberbullying.com/cyberbullying/que-es-el-ciberbullying/

Askauskas,J., \& Stoltz, A. D. (2007). Involvement in traditional and electronic bullying among adolescents. Developmental Psychology, 43, 564-575.

Schultze-Krumbholz, A., \& Scheithauer, H. (2009). Socialbehavioral correlates of cyberbullying in a German student sample. Zeitschrift für Psychologie/Journal of Psychology, 217(4), 224-226.

Secretaria de Educación de Duitama (2018). Caracterización del sector educativo. Proyecto de modernización de $\mathrm{Se}$ cretarias de Educación. Recuperado de http://semduitama.gov.co/sem2020/archivosem/DEFINITIVO\%20 CARACTERIZACI\%C3\%93N\%20AGOSTO\%20 2018.pdf

Slonje, R., \& Smith, P. K. (2008). Cyberbulling: another main type of bullying? Scandinavian Journal of Psychology, 49, 147-154.

Smith, P., Mahdavi, J., Fisher, S., Russel, S., \& Tippett, N. (2008). Cyberbullying: its nature and impact in secondary school pupils. Child psychology and psychiatry, 49(4), 376-385.

Smith, P. K. (2006). Ciberacoso: naturaleza y extensión de un nuevo tipo de acoso fuera y dentro de la escuela.Memorias del Congreso de Educación, Palma de Mallorca, pp. 1-16.

Standler, R. B. (2002). Computer Crime. Recuperado de http:// www.rbs2.com/ccrime.htm

Violence Prevention Works. (s.f.). Safer Schools, Safer Communities. Home of the Olweus Bullying Prevention Program. 
What is Cyber Bullying? Recuperado de http://www. violencepreventionworks.org/public/cyber_bullying.page Walrave, M., \& Heirman, W. (2011). Cyberbullying: predicting victimisation and perpetration. Children and Society, 25, 59-72.

Williams, K., \& Guerra, N. (2007). Prevalence and predictors of Internet Bullying. Journal of Adolescent Health, 41, S14-S21.

Ybarra, M., \& Mitchell, K. (2004). Online aggressor/targets, aggressors, and targets: A comparison of associated youth characteristics. Journal of Child Psychology and Psychiatry, 45, 1308-1316. 


\title{
Población LGTBI en contextos penitenciarios: retos de actuación en el uso de las nuevas tecnologías para las ciencias sociales
}

\author{
Luis Felipe Cardona Herrera*
}

\section{Resumen}

En este artículo de reflexión se pretende analizar las percepciones que tiene la población LGTBI en la cárcel La 40 frente a las condiciones de habitabilidad, lo cual hace emerger algunos retos de actuación en la implementación de nuevas tecnologías para las ciencias sociales en el ejercicio profesional.

En primera instancia se hace el planteamiento del problema; seguido a esto, se expone su justificación en el marco de la pertinencia, la implicabilidad y la bioética de la investigación; en un tercer momento se expone el marco metodológico, el cual es de corte cualitativo, sustentado en los paradigmas fenomenológicos, de interaccionismo simbólico

* Estudiante de séptimo semestre del programa de Trabajo Social, Universidad Libre, Seccional Pereira, Facultad de Derecho, 2017. Semillero Derechos Emergentes - DEMER. Correo electrónico: luisf-cardonah@unilibre.edu.co 
y el hermenéutico. La investigación tiene un enfoque de derechos y diferencial teniendo en cuenta la población, además se utilizó la técnica de revisión documental; en un cuarto apartado se desarrolla el marco teórico que sustenta la investigación; finalmente, en el desarrollo se presentan las ideas principales en dos apartados, el primero tiene que ver con la realidad de la población LGTBI en las cárceles de Colombia, y el segundo contiene la caracterización de la población LGTBI de la cárcel La 40; se finaliza con algunas reflexiones y conclusiones del avance investigativo.

Palabras clave: contexto penitenciario, percepciones, población LGTBI, condiciones de habitabilidad, exclusión.

\section{Abstract}

In this, article of reflexion, it is intended to analyse the perceptions that the LGTBI population has in the prison La 40 against the conditions of habitability, which makes emerge some challenges in the implementation of new technologies for the social sciences in professional practice.

In the first instance, the approach to the problem is made; this is followed by its justification in the context of research relevance, involvement and bioethics; in a third moment the methodological framework is exposed, which is of qualitative cut, sustained in the phenomenological paradigms, symbolic interactionism and hermeneutic, the investigation has a focus of rights and differential taking into account the population, in addition, the technique of documentary review was used; a fourth section develops the theoretical framework underpinning research; in the development, the main ideas are presented in two sections, the first one has to do with the reality of the population LGTBI 
in the prisons of Colombia, and the second one contains the characterization of the LGTBI population of the prison La 40; it ends with some reflections and conclusions of the research progress.

Key words: penitentiary context, perceptions, LGTBI community, conditions of habitability, exclusion.

\section{Introducción}

Los actos más viles, cual hierbas venenosas crecen lozanos en el aire de la prisión. Sólo aquello que en el hombre es bueno alli se arruina y se marchita: la pálida angustia guarda el pesado portal y el guardián es la desesperación. [...] Cada celda angosta que habitamos es una oscura letrina maloliente y cada apertura que cierran las barras es fétido aliento de muerte viviente; $y$ todo, menos la lascivia, se reduce a polvo en la máquina Humana. ÓsCar WiLDE (encarcelado por ser gay)

En Colombia la población LGTBi ha sido históricamente transgredida, estigmatizada y excluida por parte de la sociedad, la cual limita su libre desarrollo de vivir y vulnera sus derechos como seres humanos.

En los contextos penitenciarios este tipo de exclusión se hace aún más evidente, lo cual se ve materializado en múltiples expresiones de discriminación, condiciones de 
habitabilidad inhumanas, dificultad de relaciones en el establecimiento, entre otros. Para esto se han realizado avances en términos legales por medio de tutelas y exigibilidad de derechos donde el INPEC ha incluido esta población en sus lineamientos como una población de especial protección, dando mayor visibilidad a esta comunidad y protección a su integridad personal, aunque esto no siempre garantiza la integración efectiva de la población LGTBI en los contextos penitenciarios.

Por tal motivo, en la Ley 1709 del 2014, en su artículo $2 .^{\circ}$, se incluye el enfoque diferencial que "reconoce que hay poblaciones con características particulares en razón de su edad, género, religión, identidad de género, orientación sexual, raza, etnia, situación de discapacidad y cualquiera otra. Por tal razón, las medidas penitenciarias contenidas en la presente ley contarán con dicho enfoque". Esto es un avance importante en materia de protección y reestablecimiento de derechos para esta comunidad.

Ahora bien, en los contextos penitenciarios, la población LGTBI se ve constantemente transgredida, lo que genera un continuo deterioro y desequilibrio en su calidad de vida. Existe presión en las relaciones que se entretejen en este contexto y esto crea ambientes inadecuados para su desarrollo humano, social y mental que atentan contra su dignidad humana.

En cuanto a los datos estadísticos en los últimos cuatro años, el dato promedio de personas de la población LGTBI en contextos penitenciarios de nueve departamentos de Colombia es de 800 personas. "Según el censo, las mujeres lesbianas y bisexuales representan la mayor densidad poblacional, seguidas de los hombres gay y de las personas trans" (Colombia Diversa, 2014, p. 7). Lo anterior demuestra que 
un $0,7 \%$ de la comunidad carcelaria pertenece a la población LGTBI y solo el $31 \%$ de las cárceles realiza un censo de población LGTBi, lo que dificulta el reconocimiento de esta comunidad en los contextos penitenciarios. En la cárcel La 40 son veinte las personas que reconocen pertenecer a la población LGTBI, aunque se presume que existen más personas con orientación sexual diferente.

Si bien la población LGTBI se hace cada vez más grande, de igual forma crece la discriminación hacia estas comunidades. Es por esto que emerge la pregunta: ¿Cuáles son las percepciones en las condiciones de habitabilidad de las personas que pertenecen a la población LGTBI en la cárcel La 40 en la ciudad de Pereira? Allí los datos dicen que la segregación se manifiesta en su cotidianidad, sobre todo cuando los individuos se encuentran privados de la libertad, pues la falta de tolerancia y el reconocimiento de la diferencia por parte de la comunidad carcelaria generan problemáticas e impiden su desarrollo. Así las cosas, el objetivo de esta investigación consiste en analizar las percepciones que tiene la población LGTBI en cuanto a las condiciones de habitabilidad en la cárcel La 40 de la ciudad de Pereira, con miras a identificar los espacios donde interactúan los sujetos y las relaciones que se entretejen en el contexto, y caracterizar la población investigada para hallar la necesidad de nuevas tecnologías para su atención.

De igual forma, la condición física del contexto penitenciario ha presentado históricamente déficits grandes en lo referente a las condiciones de habitabilidad, como lo es la salubridad, la cual presenta graves problemas relacionados con el suministro de agua, la falta de higiene de los espacios y ambientes comunes, y la infraestructura que es inadecuada. 
Todo esto genera serios problemas de control materializados en enfermedades de todo tipo.

Lo anterior configura este concepto de pertinencia en la investigación, pues se está dando respuesta a una demanda histórica de discriminación y segregación que se acentúa aún más en los contextos penitenciarios.

Por otro lado, la investigación posibilita la construcción de proyectos, programas, planes y políticas que incluyan e involucren a esta población minoritaria con el fin de reestablecer derechos y satisfacer sus necesidades sentidas, tratando de generar procesos que impliquen voluntad, participación y empoderamiento por parte de los sujetos que hacen parte de la investigación.

Finalmente, los integrantes de la población LGTBi serán investigados como sujetos activos, capaces de pensar, de generar y provocar transformaciones, teniendo en cuenta las condiciones que se deberán afrontar en el proceso, ya que se encuentran privados de la libertad y esto influye de manera determinante en la investigación por las normas que rigen el contexto penitenciario. Por tal motivo deberán beneficiarse y no perjudicarse, y es por esto que la investigación es de riesgo mínimo.

\section{Metodología}

Esta investigación es de tipo cualitativo, es decir, "estudia la realidad en su contexto natural, tal y como sucede, intentando sacar sentido o interpretar los fenómenos de acuerdo con los significados que tienen para las personas implicadas" (Rodríguez y Gil, 1996, p. 32). Siendo así, la investigación cualitativa es un proceso inductivo mediante el cual se posibilita alcanzar conclusiones generales partiendo de hipótesis particulares; además, analiza múltiples realidades que se 
generan en las intersubjetividades, desde una óptica amplia e interpretativa que comprende la totalidad. Por lo tanto, esta investigación no es lineal sino flexible, lo que lleva a profundizar y contextualizar los resultados por medio del análisis y las explicaciones.

De acuerdo con lo anterior y teniendo en cuenta que el tipo de investigación es cualitativo, los enfoques paradigmáticos que se tuvieron en cuenta fueron el hermenéutico, el fenomenológico y el interaccionismo simbólico.

Hans-Georg Gadamer, quien, siguiendo a Heidegger, "enfatiza en el aspecto ontológico y en la hermenéutica", sostiene que "el ser del hombre reside en comprender. Esto requiere del reconocimiento de un sujeto consiente y por tanto con capacidad de reconocer su historicidad"(Cárcamo, 2005 , p. 207). Lo anterior aporta a la investigación social una mirada holística del contexto en el cual se encuentran inmersos los actores sociales. En este caso, es importante no desconocer la historicidad de los sujetos de investigación, pues ello aportará aspectos relevantes en cuanto a la compresión de la realidad; además, es importante tener en cuenta su cultura, creencias, ideologías, pensamientos, hábitos, costumbres, entre otros, que sin duda median las percepciones y su desarrollo como persona.

La fenomenología resultó ser para esta investigación el método que permitió analizar las percepciones en las condiciones de habitabilidad de la población LGTBI en la cárcel La 40, dado que según Ponce y Paiva "el método fenomenológico se vuelve sobre los contenidos de la consciencia para reconsiderarlos. [...] Le ocupa sólo el examen de estos, en tanto son dados, y describirlos en su más pura realidad" (1995, p. 72); es decir, la fenomenología se mueve en actos de reflexión de los actores sociales, lo que permite 
comprender las problemáticas como fenómenos sociales. Lo anterior, en interacción con la hermenéutica, permite entender de mejor manera la realidad social y da aportes significativos a la investigación.

Con este método lo que se pretendió fue ahondar en el proceso cognitivo que tienen estas personas frente a las condiciones de habitabilidad, dado que ser un sujeto perteneciente a la población LGTBI en el contexto penitenciario hace emerger fenómenos que deben ser tenidos en cuenta y analizados con el fin de comprender la realidad que viven, además de explicar los significados en los que se están inmersos en la cotidianidad.

Finalmente, entre los modelos paradigmáticos se encuentra el interaccionismo simbólico que, según algunos autores, se pregunta sobre "qué conjunto común de símbolos han emergido para darle sentido a las interacciones de la gente" (s.a., s.f.). Esto permitirá identificar cómo se construyen las interacciones de los sujetos de la población LGTBI en el contexto penitenciario y cómo esas interacciones posibilitan tener unas percepciones en las condiciones de habitabilidad.

Siendo así, el interaccionismo simbólico, en diálogo con la fenomenología y la hermenéutica, faculta al investigador y le da luces teóricas para comprender el problema entendido como fenómeno social que en los contextos penitenciarios vive una persona perteneciente a la población LGTBI, lo cual se ve reflejado en las interacciones de los actores con su medio y en la cotidianidad.

Por otro lado, dado que el grupo poblacional para esta investigación son los colectivos LGTBI, es necesario tener en cuenta el enfoque diferencial, el cual emerge en el entendido de que la sociedad civil, reconocida como sujeto de derechos, debe ser atendida de acuerdo con las diferencias sociocul- 
turales, étnicas, de género, entre otros. Lo anterior permite que la investigación sea guiada por normas internacionales y nacionales, con una actitud libre de prejuicios, no enjuiciadora ni revictimizante, reconociendo la dignidad humana y su valor como ser humano, con el fin de que sean incluidas y respetadas para construir conocimiento desde sus reflexiones.

En el enfoque de derechos, según el fondo de población de las Naciones Unidas, las personas son consideradas agentes principales de su propio desarrollo, en lugar de ser simplemente receptores pasivos. Este enfoque además propende al empoderamiento para que todos conozcan sus derechos y puedan exigirlos, por lo tanto, la participación a la vez se convierte en un medio y en un objetivo.

Como técnica de recolección de información se utilizó la revisión o investigación documental que, según Galeano y Vélez (2000), “todos estos textos 'cartas, periódicos, auto biografías, informes de investigación, etc.' pueden ser 'entrevistados' mediante las preguntas que guían la investigación y se los puede 'observar' con la misma intensidad con que observa un evento o un hecho social. En este sentido, la lectura de documentos es una mezcla de entrevista y observación" (p.114). Esta técnica fue de utilidad toda vez que posibilitó la sistematización de la información tanto de bases de datos como de documentos institucionales de la cárcel La 40 de manera organizada.

\section{Marco teórico}

La categoría de percepciones y, de manera específica, su conceptualización ha ido evolucionando. Maurice MerleauPonty, fenomenólogo francés, quien quizás es uno de los teóricos de mayor relevancia en el tema, en 1945 dijo en su libro Fenomenología de la percepción que "nuestra percepción 
termina en los objetos, y el objeto, una vez constituido, se presenta como la razón de todas las experiencias que de él hemos tenido o que podremos tener" (Uranga, 1957, p. 1). Según lo anterior, la percepción está mediada por la experiencia que se tiene en la primera impresión con el objeto en particular.

Por otro lado, Vargas (1994) sostiene que una de las disciplinas que más se ha centrado en el concepto es la psicología. Así, la percepción se da a partir de procedimientos llevados a cabo por el ser humano y que al final desarrollan conocimientos mediante el reconocimiento y la interpretación, con el fin de dar significados a esa experiencia.

Una de las definiciones más cercanas a la actualidad es la propuesta por Lionel Lewkow donde dice que "refiere a las operaciones de los sistemas psíquicos, evidencia aspectos de importancia sociológica que han sido opacados por la relevancia de la noción de comunicación en la teoría de sistemas sociales" (2014, p. 1).

Por otro lado, otra variable es la de habitabilidad. Para entenderla se debe definir el concepto: "vivienda saludable desarrollado por la Organización Mundial de la Salud, abarca la prestación funcional y el adecuado desarrollo físico, social y mental de las condiciones de salud, la seguridad, higiene comodidad y privacidad" (C., F. \& Valderrama, 2010). Este concepto proporciona una visión más amplia de todos los factores que incluye la definición de habitabilidad, pues esta puede referirse a la satisfacción que uno obtiene en un determinado escenario o grupo de escenarios; o al atributo de los espacios construidos para satisfacer las necesidades objetivas y subjetivas de los individuos y grupos que las ocupan, es decir, las esferas psíquicas y sociales de la existencia. 
Los estudios de Hancock (2002) sobre la relación entre las condiciones de habitabilidad y la salud desde el ambiente urbano incluyen seis dimensiones para generar un ecosistema urbano saludable: "la calidad física del ambiente urbano, la calidad del ambiente construido, el impacto del ecosistema urbano sobre los ecosistemas naturales, la salud de la comunidad urbana como entidad social, la salud de la comunidad biótica y el estado de salud de la población humana urbana" (Ceballos-Ramos, 2015). Esto implica nuevos modelos tecnológicos para la atención a las comunidades.

Es de suma importancia resaltar que existen escenarios donde las condiciones de habitabilidad no son adecuadas, ya que carecen de servicios públicos, de estructuras físicas, de recursos básicos para vivir dignamente, de acceso a la educación y al trabajo, tienen dificultad en el establecimiento de relaciones, un escaso o nulo acceso a tecnológicas, entre otros.

Dado que la comunidad LGTв hace parte de una de las variables de la pregunta de investigación, se hace necesario contar con un acercamiento teórico que ayude a profundizar más en el tema. Según lo declarado por el INPEC en la Resolución 006349 de diciembre del 2016 las siglas de la comunidad LGTBI se definen como:

Hombre gay: Hombres que se sienten emocional, sexual y románticamente atraídos a otros hombres.

Mujer lesbiana: Mujeres que se sienten emocional, sexual y románticamente atraídas a otras mujeres.

Bisexual: personas que se sienten emocional, sexual y románticamente atraídas a hombres y mujeres.

Persona Trans: cuando la identidad de género de la persona no corresponde con el sexo asignado al nacer. Las personas 
trans construyen su identidad independientemente del tratamiento médico o intervenciones quirúrgicas.

Persona intersex: todas aquellas situaciones en las que la anatomía sexual del individuo no se ajusta físicamente a los estándares culturalmente definidos para el cuerpo femenino o masculino. (p. 2-3)

Por otro lado, se toma como referencia lo planteado por Parra Pérez (2015): “las cárceles en Colombia en los últimos años, han tenido diversidad de problemáticas sociales, que atentan contra los derechos humanos, y la integridad humana, lo cual ha puesto en alerta a las autoridades estatales, las cuales, por medio de ley y respaldos de entidades internacionales, propicien un ambiente favorable a los reclusos en general" (p. 2).

Por lo anterior se concluye que en los centros penitenciarios de Colombia existen problemáticas que atentan contra los derechos humanos, uno de ellos es la violencia psicológica, verbal y física hacia la población LGTBI por parte tanto de los mismos internos como del personal administrativo. Por ello, las entidades estatales han tomado algunas medidas para minimizar la violencia hacia esta comunidad.

En esta misma línea Monsalve dice que "un beso y una manifestación de afecto entre lesbianas, gay, bisexuales, personas trans - LGBT- es, comúnmente, uno de los mayores detonantes de violencia y discriminación al interior de las cárceles [...]" (2015, p. 9). De acuerdo con lo anterior, se nota cómo en la sociedad colombiana sigue siendo un tabú el hecho de ser LGTBI, pero esto se aumenta aún más cuando las personas se encuentran en contextos penitenciarios, pues allí sufren todo tipo de discriminación y segregación 
que vulnera sus derechos e impide el libre desarrollo de su personalidad.

Finalmente, según el INPEC, el término cárcel "hace referencia a la conjugación entre el espacio físico en el cual se encuentra la persona privada de la libertad y su entorno, donde se desarrolla un estilo de vida particular de supervivencia, adaptación, sometimiento, interacción cultural, social y educativa dentro del sistema" (INPEC, 2016, p. 5). Este espacio se configura en un contexto penitenciario donde las personas privadas de la libertad habitan y conviven entre ellos, adquiriendo habilidades para la vida con el fin de alcanzar la resocialización, que es el fin último del proceso de privación de libertad.

Por otro lado, "un establecimiento carcelario puede concebirse de forma simple como un establecimiento donde son internadas las personas detenidas por el sistema penal del Estado, bien sea en desarrollo o cumplimiento de un proceso o una condena en razón a un sistema judicial que le responsabiliza de la comisión de delitos" (Huertas, Trujillo y Silvera, 2015, p. 2).

\subsection{Comunidad LGTBi: una mirada desde la realidad} penitenciaria y carcelaria colombiana

Según un estudio realizado por Castañeda, Puerto y Antonio "se ha podido demostrar que el colectivo LGTBi es discriminado por su condición sexual diversa además de ser agredidos con determinados actos vulnerando su integridad, seguridad y vida. Pasando por alto algunos de los 'Principios Básicos para el Tratamiento de los Reclusos', adoptados por la Asamblea General de las Naciones Unidas en su resolución 45/11, de 14 de diciembre de 1990" (2013, p. 9). 
Teniendo en cuenta lo anterior, se puede ver cómo a pesar de que Colombia ha avanzado en materia del reconocimiento de los derechos humanos para las personas que hacen parte de la población LGTBI en contextos penitenciarios, todavía se siguen presentando hechos discriminatorios y de segregación hacia estas comunidades, y más aún cuando se trata de centros penitenciarios masculinos, donde estas personas deciden ocultar su orientación sexual precisamente para no sufrir ningún tipo de maltrato por parte de sus compañeros ni del personal administrativo. En este mismo informe Castañeda Puerto plantea que para "los funcionarios del penal es una constante el maltrato a los reclusos homosexuales, algunas veces lo hacen por diversión [...]"(2013, p. 10). Con lo cual se hace necesario tomar medidas urgentes por parte del Estado como garante de derechos para su reconocimiento como seres iguales y dignos ante la ley, independientemente de su condición sexual, empezando por el personal administrativo que debe garantizar la protección del interno.

Camino Madiedo, en el curso del caso 11656 Martha Lucía Álvarez vs. Colombia, plantea que:

Cuando se observan las estructuras sociales latinoamericanas, es evidente que las instituciones están diseñadas para suplir las necesidades de los sujetos que obedecen a los sistemas reglamentarios de tipo heteronormativo y patriarcal. En este caso particular, se toma en cuenta el Sistema Penitenciario Colombiano en el que tanto la infraestructura social como el patrón de planeación interno es determinado por la heteronormatividad antes mencionada, es decir, las cárceles de hombres son diseñadas exclusivamente para hombres en términos genéticos, cuya 
identidad de género es masculina y además su orientación sexual es heterosexual. (2013, p. 5)

Por lo anterior, se evidencia cómo no solo en los centros penitenciarios se han sesgado en un pensamiento lineal o en un parámetro que debe cumplirse en cuanto a la condición sexual del ser humano, sino que también a la sociedad en general no se le ha preparado lo suficiente como para otorgar al otro ese reconocimiento a la diferencia. Por ello se hacen necesarias no solo normas que regulen y propendan a la inclusión e integración efectiva de la población LGTBI en contextos penitenciarios, sino también estrategias de concientización y de respeto a la diferencia a todas las personas que hacen parte de este grupo de especial protección, desde nuevos modelos pedagógicos, tecnológicos y culturales que aporten a su autorreconocimiento y participación.

Asimismo, según el in PEc (2017), dentro de sus principios rectores tiene en cuenta el enfoque diferencial "reconoce que hay poblaciones con características particulares en [...] expresión de género, orientación sexual, diversidad corporal [...]. Por tal razón, las medidas penitenciarias y carcelarias del presente reglamento contarán con dicho enfoque".

Dentro del principio anteriormente mencionado se puede deducir que el INPEC tiene en cuenta a la población LGTBi dentro de sus políticas institucionales como una comunidad que demanda ser visibilizada y atendida, por lo cual plantea el enfoque diferencial como principio que permite el reconocimiento de condiciones distintas dentro de la sociedad como sujetos de derechos. Contradictoriamente dentro de las cárceles colombianas, y según la revisión documental, falta avanzar un poco más en el aspecto del enfoque diferencial pues, según algunos estudios, las personas que tienen otras 
orientaciones sexuales dentro de los contextos penitenciarios son constantemente vulneradas y maltratadas, no solo por parte de los demás internos, sino también por parte de los funcionarios, el área administrativa y por sus familias.

De la misma forma, cabe mencionar que según documentos, en la cárcel La 40 de la ciudad de Pereira cuentan con unos lineamientos técnicos en cuanto a la atención de la población LGTBi en prisión, tanto de mujeres como de hombres. Por lo tanto el inPec, desde el año 2010, ha encaminado acciones que buscan garantizar la protección de la población perteneciente a los sectores LGTBI desde su marco legal, teniendo en cuenta la Normatividad Internacional, la Declaración Universal de los Derechos Humanos, los Principios de Yogyakarta, el Pacto Internacional de Derechos Civiles y Políticos y la Resolución aprobada por el Consejo de Derechos Humanos; y, por otro lado, la Normatividad Nacional en cuanto a la Constitución Política de Colombia, la Ley 1709 del 2014, además de las diferentes sentencias que reconocen los derechos de las personas LGTBI dentro de los contextos penitenciarios.

Finalmente, es importante tener en cuenta algunos de los censos realizados por el INPEC en cuanto a la población LGTBI con el propósito de realizar acciones para promover programas a favor de esta comunidad. Para ello, Monsalve comenta que "según el censo del INPEC, en los últimos cuatro años el número promedio de personas LGTBI privadas de la libertad es de 800" (2015, p. 9). Para el gobierno, este censo (que se viene haciendo desde el año 2011) tiene como objetivo obtener una aproximación de la cantidad de personas LGTBI recluidas en las cárceles del país, no porque no hubiese personas con diversidad sexual en prisión, sino porque esta 
unidad está siendo visibilizada por la demanda de atención que ha ido emergiendo en la actualidad.

\subsubsection{Condiciones de habitabilidad: caracterización de la comunidad LGTBI de la cárcel La 40} Según la revisión documental y la consulta con fuentes secundarias con las practicantes de Trabajo Social realizadas en la cárcel La 40 de la ciudad de Pereira, las personas pertenecientes a la comunidad LGTBI se configuran en una población minúscula, dado que, según estudios de Caracol Radio (2017), la población neta del centro penitenciario carcelario es de "más de mil 200 internos dentro de la cárcel y otros mil 50 que están con el beneficio de prisión domiciliaria”. Son alrededor de veinte hombres que se autorreconocen abiertamente pertenecientes a la comunidad LGTBI, entendiendo que esta cifra podría aumentar con las personas no autorreconocidas. Sus edades varían entre los 22 y los 50 años de edad, lo que indica que en su mayoría están en el ciclo vital de adultez temprana y media. Se identificó también que el género con el que se reconocen en su mayoría es el gay, seguido por los transexuales y solo una persona se reconoce como bisexual.

En cuanto al nivel educativo de la población perteneciente a la comunidad LGTBi, la mayoría está en básica de primaria y secundaria, solo dos personas son universitarias, y todos y todas saben leer y escribir. Por otro lado, la actividad económica que ejercían antes de ingresar al centro penitenciario y carcelario era de trabajadores(as) sexuales, peluqueros(as) y comerciantes.

Por otro lado, entre los delitos por los cuales fueron condenados están el hurto y concierto para delinquir. El tiempo de condena oscila entre dos y seis años. Las personas 
que cuentan con redención de la pena realizan actividades artesanales, industriales y estudian, aunque algunas — sobre todo las personas transexuales - también pasan su tiempo arreglando uñas y en peluquería.

Dentro de las actividades institucionales con que cuenta esta comunidad está la participación en campañas de salud sexual reproductiva y en campañas de derechos de la población LGTBI, lo que les permite conocer algo acerca del tema. Sumado a esto, la Alcaldía de Pereira tiene un programa específico para esta comunidad, pero no está siendo ejecutado actualmente.

En temas de salud, el acceso es deficiente dada la sobrepoblación existente en el establecimiento. A esto se suman los canales de comunicación ineficientes entre las instituciones, por lo cual es necesario generar iniciativas desde las tecnológicas de la comunicación y la información que agilicen los procesos, dado que la salud es un derecho que tiene que ser garantizado por los centros penitenciarios.

Por otro lado, la educación formal e informal para el trabajo y el desarrollo humano, aunque en términos generales es garantizada para la comunidad, carece de modelos pedagógicos incluyentes y de conectividad efectiva, ya que por normatividad y seguridad del INPEC la educación virtual es limitada, lo cual genera dificultades y barreras en el proceso formativo de la población.

En la cárcel La 40 se ha destinado un pabellón donde habitan la población LGTBi, los adultos mayores y las personas que ingresan por delitos como violación. Esto con el fin de proteger su integridad, ya que el patio 2 se considera uno de los más tranquilos. E1 $70 \%$ de las personas privadas de la libertad, pertenecientes a la comunidad, dice estar de acuerdo con un pabellón privado donde estén ellos exclusivamente, 
pues esto los hace sentir más cómodos y protegidos, aunque algunos prefieren estar en otros patios.

El día a día de estas personas se caracteriza por ser una jornada monótona, ya que en las horas de la mañana les cierran las celdas desde las 6:00 a.m. hasta el mediodía. A las 12 p.m. abren las puertas para descansar y a la 1 p.m., deben regresar al patio hasta las 5 p.m., salvo si están haciendo actividades laborales, pues trabajan en peluquería y arreglando uñas a los mismos internos. Los que se reconocen como gays pintan en madera o actúan como monitores en 'educativas' (ciclos lectivos especiales integrados - CLEI-).

La comunidad manifiesta que el ambiente es tranquilo y las relaciones son buenas; mencionan que desde que nadie se meta con ellos, ellos no se meten con nadie. Como miembros de la población LGTBi se relacionan entre sí y se sienten a gusto estando juntos. Aunque existen expresiones de discriminación y segregación por parte de sus compañeros y del cuerpo de custodia y vigilancia, mencionan que se asemejan a las actitudes que tiene la sociedad frente a ellos.

La Corte Interamericana de Derechos Humanos ha establecido de manera constante, a lo largo de su jurisprudencia, que "la detención en condiciones de hacinamiento, con falta de ventilación y luz natural, sin cama para el reposo ni condiciones adecuadas de higiene, en aislamiento e incomunicación o con restricciones al régimen de visitas constituye una violación a la integridad personal" (Rodriguez, 2015, p. 18).

Sin embargo, frente a las condiciones de habitabilidad, hay que decir que los espacios físicos son reducidos: las medidas de las celdas son de 2,20 m de ancho por 4,20 m de fondo y $3 \mathrm{~m}$ de alto, e incluso algunos reclusos duermen en los pasillos por el hacinamiento existente en el establecimiento, lo que 
les obliga a guardar sus cosas personales en otro lugar y eso genera rivalidades por la pérdida de objetos. Además, solo se cuenta con un baño y una ducha para todas las personas que habitan en este patio que es el más pequeño de todo el centro penitenciario. Es imponte mencionar que la cárcel les permite ingresar, además de sus útiles de aseo, su maquillaje y objetos personales particulares, dada su condición e identidad sexual.

Por otro lado, la población encuestada del centro carcelario expresa que "la habitabilidad influye en la construcción de vínculos afectivos como la amistad y el noviazgo, porque la mayoría tiene una relación sentimental por fuera de este contexto y algunos en los diferentes patios". El proceso normativo para el ingreso de la visita íntima es una vez al mes, lo que de alguna manera fractura la relación. Esto sumado al proceso extramural que se debe seguir con la solicitud de las visitas virtuales y demás requisitos legales que en la mayoría de los casos es demorado o negado.

Finalmente, los reclusos mencionan que a pesar de los actos discriminatorios les agrada estar en la cárcel de hombres más que en la reclusión de mujeres; refieren que "en este lugar por lo menos pueden trabajar y ganar dinero, además, los hombres no son tan complicados como las mujeres y no se generan rumores ni chismes" (PPL autorreconocida como comunidad LGTBI).

\subsubsection{Retos de actuación en las ciencias sociales}

El trabajo en área judicial, específicamente en penitenciario, se basa en el respeto de los derechos humanos y la dignidad de la persona que ha transgredido la ley. El quehacer profesional está orientado a propender al cambio y la transformación social guiado por principios como la equidad y la 
justicia social. Sumado a esto, interviene en la resolución de problemas en las relaciones humanas y en el fortalecimiento de las redes de apoyo, en el respeto por la diferencia y en la inclusión efectiva, todo con miras a promover la resocialización del interno, la no reincidencia y la prevención del delito.

Las ciencias sociales dentro de los contextos penitenciarios con la población LGTBI tienen como reto generar espacios de reconocimiento y reflexión acerca de la diferencia y la diversidad, para que los prejuicios insostenibles no den pie al rechazo, la discriminación, la segregación y mucho menos a la violencia física y psicológica de las personas que hacen parte de esta población. Es por esto que su actuación debe estar sustentada desde un enfoque de derechos humanos, procurando generar nuevos modelos pedagógicos, educativos y tecnológicos que posibiliten la inclusión efectiva de las comunidades diversas, las cuales han sido históricamente vulneradas y no tenidas en cuenta.

Dado lo anterior, la Declaración Universal de los Derechos Humanos Emergentes da luces teóricas para el abordaje de las nuevas realidades sociales y de los colectivos que no han sido visibilizados en la esfera pública. Sumado a esto, esta nueva categoría de derechos pone la mirada no solo en esta comunidad, sino también en la complejidad del contexto y en la composición como fenómeno social, en el cual se configura ser un hombre con condición sexual diversa en un centro penitenciario y carcelario.

Así mismo, la apuesta ético-política de los profesionales debe enmarcarse en la visibilización y participación de esta comunidad, propendiendo por la interacción con los demás hombres privados de la libertad, donde su rol no sea solo pintar uñas o lavar loza y ropa como se ha venido 
normalizando, sino que puedan tener voz, voto y opinión en medio de las relaciones que se entretejen.

Por otro lado, se debe generar un trabajo articulado con los entes estatales para que las políticas encaminadas a la protección de la población LGTBI se cumplan y no se queden en buenas intenciones ni mucho menos escritas en un papel, dado que todos los procesos deben ser implacables, sostenibles, pertinentes y éticamente responsables. Por ello, es necesario que desde el enfoque de la gerencia social se construyan políticas públicas desde la voz de los actores donde estos expresen sus necesidades sentidas y sean tomadas en cuenta para su reconocimiento como sujetos de derechos dentro de la sociedad, con el fin de generar no solo un producto tangible, sino corresponsabilidad, capital social y capacidad instalada, partiendo de la educación como eje central para gestionar espacios de empoderamiento y respeto por la diferencia dentro de los ámbitos penitenciarios que lleven al reconocimiento del otro como sujeto de derechos.

Es necesario también que cada acción encaminada a generar bienestar en la población LGTBI en el contexto penitenciario sea tranversalizada por los enfoques de derechos y diferencial en clave a una perspectiva bioética, reconociendo al otro como igual sin importar su condición, con el fin de proteger su integridad personal y el libre desarrollo de su personalidad, dada su orientación sexual.

Además, es importante contribuir a la sensibilización social para generar espacios de oportunidades y respeto hacia la población dentro de los contextos penitenciarios, pues la acción de las ciencias sociales, en específico de los profesionales en Trabajo Social, debe propender a garantizar el derecho a ejercer la ciudadanía desde el empoderamiento y la corresponsabilidad para que los sujetos, como actores sociales y con 
características distintas, cuenten con igualdad de derechos ante la sociedad. Para esto precisamente se deben generar nuevas tecnologias que posibiliten la participación, el reconocimiento y el respeto desde la interactividad en términos de comunicación $y$ conectividad.

Finalmente, los procesos de investigación se configuran en espacios propicios para la detección de necesidades sentidas de la población, lo que posibilita la construcción de nuevas alternativas que generen bienestar a la comunidad. Por esto, la investigación es un reto para las distintas disciplinas de las ciencias sociales toda vez que no se encuentra mucha información en el tema y esta comunidad demanda ser atendida y visibilizada en estos contextos; pero, además de esto, es un reto su diseño, dado que para que sea exitosa debe estar articulada con medios tecnológicos novedosos que faciliten el acceso a la información, y por variables bioéticas, politicas y pertinentes que permitan una implicabilidad en los contextos; es decir, que los resultados sirvan para la construcción de mejores realidades sociales.

\section{Conclusiones}

Es de suma importancia resaltar que en los contextos penitenciarios existen escenarios donde las condiciones de habitabilidad no son adecuadas, ya que carecen de servicios públicos óptimos, de estructuras físicas, de recursos básicos aptos para vivir dignamente; sufren un debilitamiento de las relaciones sociales y un difícil acceso a las tecnologías en materia de educación y trabajo, entre otros. Por tal motivo, a partir de las investigaciones que se han realizado, es evidente especificar que la población LGTBI parte con una desventaja por su condición sexual, debido a que no se cuenta con las medidas oportunas para brindarle bienestar desde los 
diferentes espacios físicos, culturales, tecnológicos, sociales y de comunicación. Esto porque su condición diversa, entendida como fenómeno social por el contexto en el que se circunscribe, hace emerger nuevas necesidades que no han sido tenidas en cuenta en las cárceles de hombres, dado que estas están enmarcadas en lo heteronormativo, es decir, están pensadas para hombres heterosexuales.

La población LGTBi ha sido históricamente vulnerada, excluida y segregada. En el caso de Colombia, por muchos años esta comunidad fue tratada indignamente en los contextos penitenciarios, pero dadas las luchas sociales y el proceso evolutivo de la sociedad y los derechos humanos, se han ido incorporando normatividad que protege su dignidad humana y su integridad personal.

Se puede notar que en Colombia existen algunos avances en cuanto al reconocimiento, la normatividad y la jurisprudencia frente a las personas LGTBI en contextos penitenciarios, pero aún falta trabajo por realizar con el fin de generar espacios de respeto, participación, integración e inclusión efectiva para la población, donde los enfoques de derechos humanos, de género, quizás en clave con la Declaratoria Universal de los Derechos Humanos Emergentes y las nuevas tecnologias, juegan un papel protagónico para la atención y la satisfacción de las necesidades sentidas por este colectivo.

Por otro lado, la población LGTBI en los contextos penitenciarios demanda nuevas miradas teóricas, epistemológicas, prácticas y tecnológicas para su abordaje desde las ciencias sociales y el trabajo social, ya que, aunque la comunidad haya normalizado su rol desde el quehacer diario dentro de la cárcel, se deben generar espacios de respeto por la diferencia, la participación efectiva, el empoderamiento, la capacidad instalada y la construcción de capital social que 
les permita ser gestores de su desarrollo. Esto con el fin de que su proceso de resocialización sea exitoso y propenda a la no reincidencia del delito, fortaleciendo los procesos desde los modelos pedagógicos populares y las tecnológicas de la información y la comunicación.

Como investigadores se hace necesario contar con diferentes herramientas que generen respuestas a la pregunta de investigación formulada y metodologías flexibles que posibiliten la consecución de los objetivos, nutridas con tecnológicas que enriquezcan el quehacer propio de los profesionales. Todas estas sirven como insumo para dar una mirada holística y desde diferentes perspectivas acerca de la comunidad LGTBI dentro de los contextos penitenciarios en el territorio colombiano y en específico de la cárcel La 40.

La fenomenología como método de investigación permite describir la esencia del fenómeno que lleva a caracterizar de una mejor forma los hechos. Se hace indispensable entonces incluirla dentro de los procesos investigativos, y más aún cuando lo que se pretende es analizar las percepciones de habitabilidad de la comunidad LGTB en los contextos penitenciarios, pues es de vital importancia para conocer los acontecimientos vividos y percibidos por ellos.

Finalmente, las investigaciones sociales deben generar acciones más humanizadas para alcanzar la libertad de sentir, actuar y pensar, respetando la diferencia del otro y reconociéndolo como sujeto de derechos.

\section{Referencias}

Añaños, F. et al. (2013). Aproximación a los contextos en prisión. Una perspectiva socio educativa. Recuperado de https:// recyt.fecyt.es/index.php/PSRI/article/view/37996/21436 
Bohórquez, V. (2015). Del amor y otras condenas: personas LGTBI en contextos penitenciarios Colombianos. Recuperado de lombiadiversa.org/colombiadiversa/documentos/informes-dh/colombia-diversa-personas-LGBT-en-carcelesde-colombia-2013-2014.pdf

Caracol Radio (2017). Cárcel de Pereira con alto hacinamiento y riesgo de colapso. Recuperado de http://caracol.com.co/ emisora/2018/05/02/pereira/1525265700_764389.html

Cárcamo, H. (2005). Hermenéutica y análisis cualitativo. Cinta de Moebio. Revista de Epistemología de Ciencias Sociales, (23). Recuperado de http://www.auroradechile.uchile.cl/ index.php/CDM/article/viewFile/26081/27 386

Carvajar, P. (2013). El reconocimiento de derechos a la comunidad LGTBI. Recuperado de https://dialnet.unirioja.es/servlet/ articulo?codigo $=4919267$

Clavijo, A. et al. (2011). ¿Cómo se manifiesta la discriminación a la comunidad LGTBI en las cárceles colombianas? Recuperado de http://repository.unimilitar.edu.co/ bitstream/10654/6932/2/ClavijoCastanedaAngelicaSofia2011.pdf

Congreso de la República (2014). Ley 1709 del 2014. Recuperado de http://search.proquest.com/docview/1762314007?pqorigsite $=$ gscholar

Coyle, A. (2009). La administración penitenciaria en el contexto de los derechos humanos. Manual para el personal penitenciario. Recuperado de http://www.justicia.gob.ec/wpcontent/uploads/2015/08/LA-ADMNISTRACIONPENITENCIARIA-EN-EL-CONTEXTODE-LOSDERECHOS-HUMANOS.pdf

Del Pozo, F., \& Añaños, F. (2012). La educación social penitenciaria: $\dot{\complement}$ De dónde venimos y hacia dónde vamos? Recuperado 
de https://revistas.ucm.es/index.php/RCED/article/viewFile/41191/39392

DNP (s. f.). Enfoque de orientaciones sexuales e identidades de género. Recuperado de https://colaboracion.dnp.gov.co/ CDT/Poltica\%20de\%20Vctimas

Fabbri, M. (s. f.). Las técnicas de investigación: la observación. Recuperado de http://www.fhumyar.unr.edu.ar/escuelas/3/materiales $\% 20 \mathrm{de} \% 20$ catedras/trabajo\%20de\%20 campo/solefabri1.htm.

Galeano, M. (2012). Estrategias de investigación social cualitativa. El giro en la mirada. Medellín: La Carreta Editores. Huertas, O. et al. (2015). Perspectivas de los derechos humanos y la libertad en contextos de sistemas penitenciarios. Recuperado de http://search.proquest.com/docview/1762314007?pqorigsite $=$ gscholar

Justiniano, C. et al. (2010). Parámetros y estándares de habitabilidad: calidad en la vivienda, el entorno inmediato y el conjunto habitacional. Recuperado de http://s3.amazonaws. com/academia.edu.documents

Lewcow, L. (2014). Aspectos sociológicos del concepto de percepción en la teoria de sistemas sociales. Recuperado de http:// www.revistaderechopublico.uchile.cl/index.php/RMAD/ article/viewArticle/32957

Merleau-Ponty, M. (1957). Fenomenología de la percepción. Recuperado de http://s3.amazonaws.com/academia.edu. documents/42807333/51394821-MERLEAU-PONTYMaurice-Fenomenologia-de-LaPercepcion.pdf?AWS AccessKeyId=AKIAIWOWYYGZ2Y53UL3A\&Exp ires $=1488152127 \&$ Signature $=u K C \% 2 B i 5 c l p J v U v x R V$ DhUyd4wp4yI\%3D\&response-content-disposition=in line\%3B\%20filename\%3DMaurice_Merleau-Ponty.pdf 
Moreno,J. (2016). El derecho fundamental a la visita intima entre personas de la comunidad LGTBI en las prácticas penitenciarias en Colombia. Recuperado de http://www.pensamientopenal.com.ar/system/files/2016/08/doctrina43930.pdf

Oviedo, G. (2004). La definición del concepto de percepción en psicología con base en la Teoría Gestalt. Recuperado de http://www.scielo.org.co/pdf/res/n18/n18a10.pdf

Pérez, L. (2015). La verdad de la comunidad LGTBI en las cárceles colombianas. Recuperado de http://repository.unimilitar. edu.co/handle/10654/14030

Prosperidad Social (s. f). Grupo de enfoque diferencial. Recuperado de http://www.prosperidadsocial.gov.co/ent/gen/ prg/Documents/Descripci\%C3\%B3n\%20Enfoque\%20 Diferencial.pdf

Quesada, M., Matus, T., Rodríguez, N., Onetto, L., Ponce, M., \& Paiva, D. (1995). Perspectivas metodológicas en Trabajo Social. ALAETS - CELATS. Recuperado de http://www. ts.ucr.ac.cr/binarios/pela/pl-000380.pdf

Rodríguez, G., \& Gil, J. (1996). Metodología de la investigación cualitativa. Recuperado de http://media.utp.edu. co/centro-gestion-ambiental/archivos/metodologia-dela-investigacion-cualitativa/investigacioncualitativa.doc Rueda, S. (1996). Habitabilidad y calidad de vida. Recuperado de http://scholar.googleusercontent.com/scholar?q=cac he:B9tmCpIRWzgJ:scholar.google.com/+condiciones+ de+habitabilidad\&hl=es\&as_sdt=0,5

Ruiz, J. (2012). Metodología de la investigación cualitativa. España: Universidad de Deusto.

Salgado, J. (2011). Lidiando con la diferencia. Respuestas desde la justicia constitucional ecuatoriana y colombiana. Recuperado de http://search.proquest.com.sibulgem. 
unilibre.edu.co:2048/central/docview/1640765774/ DC0765D738974552P

Sampieri, R., Collado, F., \& Baptista L. (2014). Metodología de la investigación (6. ${ }^{\mathrm{a}}$ ed.).México: McGraw Gil Education. UnFPA (2003). El enfoque basado en los derechos humanos. Recuperado de http://www.unfpa.org/es/el-enfoque-basadoen-los-derechos-humanos

Vargas, L. (1994). Sobre el concepto de percepción. Recuperado de http://biblioteca.ues.edu.sv/revistas/10800277-4.pdf 



\title{
\#ClicSocial \\ Participación digital para \\ la inclusión social
}

\author{
Melissa Morales Londoño \\ Brigit Joaly Zapata Muñoz*
}

\section{Resumen}

El presente artículo de reflexión, realizado en el marco de la Clínica Jurídica en Acciones de Interés Público de la Universidad Libre, Seccional Pereira, consiste en la construcción de un análisis que evidencie los avances de las nuevas tecnologías, los medios de comunicación y las redes sociales, respecto de la eliminación de barreras impuestas a las personas con discapacidad con el fin de incentivar su participación como sujetos activos dentro de una sociedad. Así, a través de dichas herramientas, se genera movilización social

* Estudiantes de cuarto y quinto año del programa de Derecho de la Universidad Libre de Pereira. Integrantes del Semillero en Derecho Constitucional Derco y de la Clínica Jurídica de Acciones de Interés Público de la Universidad Libre, Seccional Pereira. Correos electrónicos: melissa-morales1@unilibre.edu.co, brigitj-zapatam@unilibre.edu.co 
informal que busca materializar los principios del Estado social de derecho que consagra Colombia en su Constitución Política, y el reconocimiento de grupos poblacionales por medio de plataformas estratégicas e innovadoras donde se visibilice y potencien las capacidades de las personas con discapacidad en una realidad inclusiva, justificada por medio de la concientización colectiva. Todo esto bajo el entendido de que las personas con discapacidad no deben adaptarse al entorno, sino que este mismo debe ser idóneo para todos, en virtud a la diversidad funcional y de la accesibilidad universal, de manera que se generen resultados satisfactorios que reconozcan a los ciudadanos como un todo integral, participando en todos los aspectos de la vida y haciendo efectiva la dignidad humana.

Palabras clave: diversidad funcional, participación, medios de comunicación, inclusión social.

\section{Abstract}

This article of reflection within the framework of the legal clinic in actions of interest public of the Universidad Libre, Seccional Pereira, consists of the construction of an analysis that shows the progress of new technologies, media and social networks respect of the elimination of barriers imposed on persons with disabilities for participation as active subjects within a society, it is as well as informal social mobilization that seeks to realize the principles of the Social Rule of Law is generated through these tools and recognition of population groups through strategic and innovative platforms where are made visible and enhance capabilities of persons with disabilities in an inclusive reality justified by means of collective awareness; under the understanding that people with 
disabilities should not adapt to the environment, it is the environment that must be suitable for all, in virtue of functional diversity and universal accessibility, so generated satisfactory results accorded to citizens as an integral participating in all aspects of life and making effective the human dignity.

Key words: functional diversity, participation, media, social inclution.

\section{Introducción}

A un clic se conecta el mundo en tiempo real, a un clic se puede tener acceso a la información, a un clic se pueden generar cambios significativos dentro de la sociedad. Es por esto que la presente ponencia tiene como objetivo analizar el fenómeno de los medios digitales como mecanismo de incidencia social y política, en particular con los sujetos de especial protección, como lo son las personas con discapacidad. Para lograrlo se parte del impacto que constituye el litigio estratégico que desde las Clínicas Jurídicas ${ }^{1}$ se logra respecto de la enseñanza y ejercicio del derecho, donde íntegramente se puede dar solución a problemáticas sociales, permitir la participación ciudadana y la cohesión social para

1 Las Clínicas Legales de Interés Público pueden concebirse como un ámbito de trabajo jurídico tendiente a garantizar la vigencia de algunos derechos y el acceso a la justicia de determinados sectores de la población; y, al mismo tiempo, como un espacio de docencia destinado a la preparación de los estudiantes para la práctica profesional de la abogacía. A través de las Clínicas Jurídicas es posible una nueva práctica de enseñanza del Derecho a través de la investigación, que genere impacto social y procure la protección de un interés público y la garantía de derechos fundamentales. (Grupo en Derecho Constitucional - Derco. Línea de investigación en Derechos Fundamentales, 2015) 
alcanzar, fundamentalmente, la protección y reconocimiento de derechos humanos.

Desde la Clínica Jurídica de Acciones de Interés Público de la Universidad Libre, Seccional Pereira, se pretende hacer una reflexión respecto de la influencia positiva de los medios digitales o redes sociales en el ejercicio de una ciudadanía activa encaminada al reconocimiento de los derechos de las personas con discapacidad. Para esto se identifica cómo estos medios se vuelven herramientas idóneas en el reconocimiento y la protección de derechos, permitiendo la inclusión social como un reto más dentro de la sociedad colombiana.

A partir de la premisa anterior, la presente reflexión se desarrollará en cinco momentos consistentes en analizar (i), la participación ciudadana desde las Clínicas Jurídicas, (ii) el concepto de ciudadanía, (iii) la movilización social a través de los medios de comunicación, (iv) las personas con diversidad funcional, (v) y el \#ClicSocial, un paso hacia la transformación; finalmente de presentan las conclusiones.

\subsection{Análisis de la participación ciudadana desde las Clínicas Jurídicas}

El litigio estratégico de alto impacto que se busca dentro de las clínicas jurídicas parte de la identificación de una problemática social, y como proceso de intervención se enfoca en conseguir y ofrecerle una solución integral a través de un proceso sistematizado que contiene varios componentes, uno de ellos es el político.

Si se tiene en cuenta que las Clínicas Jurídicas cumplen un papel político dentro de la sociedad, en tanto las problemáticas que se pretenden intervenir deben estar orientadas a incidir "de forma directa o indirecta en el proceso de discusión, toma y ejecución de las decisiones"(Correa Montoya, 2008, 
p. 255), el presente análisis dentro de la Clínica Jurídica en Acciones de Interés Público resulta pertinente, pues busca reflejar cómo la construcción de participación ciudadana desarrolla en mayor medida "la capacidad de incidencia de las esferas del gobierno, con la intención que la ciudadanía y sus organizaciones aumenten su nivel de convocatoria que les permita influir sobre los principales actores que toman las decisiones"(MCD, 2007, citado en Correa Montoya, 2008, p. 256), lo que genera entonces un cambio social.

\subsection{De la ciudadanía}

Frente a lo anterior, dicha participación se ve limitada cuando se trata de personas con discapacidad. Para entrar en este debate, se desarrollará inicialmente una reflexión respecto de la ciudadanía, no desde una concepción legal sino como una actividad deseable, donde la calidad de la ciudadanía depende de la participación dentro de la comunidad, tal como hacen alusión Kymlicka y Norman (2002, p. 3) en el "Retorno del ciudadano".

Así pues, como establece Marshall, citado por Kymlicka y Norman (2002, p. 4): "la ciudadanía consiste esencialmente en asegurar que cada cual sea tratado como un miembro pleno de una sociedad de iguales [...]. Al garantizar a todos los derechos civiles, políticos y sociales, este Estado asegura que cada integrante de la sociedad se sienta como un miembro pleno, capaz de participar y de disfrutar de la vida en común. Allí donde alguno de estos derechos sea limitado o violado, habrá gente que será marginada y quedará incapacitada para participar”.

Esto es, la ciudadanía no siempre aporta una experiencia común de identidad y no incluye en pie de igualdad a los grupos históricamente excluidos. 
En esta línea, además de los derechos que se proclaman en virtud de la ciudadanía, se debe hablar también de deberes o responsabilidades, las cuales se tienden a omitir; adicional a ello, Mulgan (1991), citado por Kymlicka y Norman (2002, p. 7), advierte que "no sólo atribuya responsabilidades sino también garantice la capacidad de hacer uso de ella". Aquí se evidencia la importancia de no quedarse en la mera proclamación de derechos y deberes, sino que se debe garantizar su materialización, es decir, contar con los medios para hacerlo.

Sin embargo, con respecto a este tema la sociedad tiene una cuota de responsabilidad frente a la capacidad del Estado a la hora de satisfacer las necesidades de todos los que componen la sociedad, especialmente de aquellos grupos poblacionales catalogados como minorías o sujetos de especial protección, como por ejemplo los adultos mayores, las mujeres, las personas con discapacidad, población LGTBI, las minorías étnicas y religiosas, entre otros. Esto es, a través de la tolerancia por la diferencia, imprescindible por parte de toda la sociedad.

Se requiere entonces que la ciudadanía sea entendida desde una concepción más amplia y completa porque "lo que el Estado necesita de la ciudadanía no se puede obtener mediante la coerción, sino solamente por medio de la cooperación y el auto-control en el ejercicio del poder privado" (Cairns y Williams, 1985, citado por Kymlicka y Norman, 2002, p. 9).

En conclusión, la ciudadanía, más que un estatus legal definido por derechos y responsabilidades, se refiere a una identidad y pertenencia a una comunidad. En términos de Marshall, se podría hablar de una "cultura compartida"; sin embargo, los grupos mencionados anteriormente, a pesar 
de que se les reconocen derechos comunes propios de la ciudadanía, se sienten excluidos de la "cultura compartida" por diversos factores como el nivel socioeconómico o simplemente por factores socioculturales, es decir, por su "diferencia" (Kymlicka y Norman, 2002, p. 18).

Según Young (1989), citada por Kymlicka y Norman (2002, p. 19), "los grupos culturalmente excluidos están en desventaja de cara al proceso político, y la solución consiste, al menos parcialmente, en proveer medios institucionales para el reconocimiento explícito y la representación de los grupos oprimidos". Ahora bien, estos grupos tienen unas necesidades específicas y particulares que solo se pueden satisfacer mediante políticas diferenciadas, pero este aspecto se desarrollará más adelante.

Finalmente, es el respeto por la diversidad lo que permitirá la inclusión de todas las personas a la sociedad.

Ahora bien, en el contexto colombiano, cuando se habla de inclusión social según la Ley 1618 del 2013, en su artículo 2. ${ }^{\circ}$, se hace referencia a:

$\mathrm{El}$ proceso que asegura que todas las personas tengan las mismas oportunidades, y la posibilidad real y efectiva de acceder, participar, relacionarse y disfrutar de un bien, servicio o ambiente, junto con los demás ciudadanos, sin ninguna limitación o restricción por motivo de discapacidad, mediante acciones concretas que ayuden a mejorar la calidad de vida de las personas con discapacidad. (Ley 1618, 2013)

\subsection{Movilización social a través de los medios de comunicación}

Desde la concepción del Estado colombiano se ha establecido como uno de sus principios fundantes el de la participación, 
implantando como mecanismos para su ejercicio los siguientes: el voto, el plebiscito, el referendo, la consulta popular, el cabildo abierto, la iniciativa legislativa y la revocatoria del mandato.

Sin embargo, además de las instituciones formales y tradicionales de participación, Peter Dahlgren en su obra The Internet, public spheres and political communication: Dispersion and Deliberation establece que deben ser incluidas las organizaciones de medios o plataformas virtuales, las cuales permiten la participación tanto en política como en temas de cultura, economía, etc. Esto gracias a que las comunicaciones de carácter masivo en internet demuestran una representación relevante en los contextos en línea dentro de la esfera pública, las cuales evidencian importantes prácticas discursivas y psicoculturales (Dahlgren, 2005, pp. 147-162).

Es a través de los diferentes medios de comunicación y de las redes sociales que los conglomerados sociales se han empezado a movilizar en favor de los derechos de las minorías. Los cambios y avances tecnológicos han permitido una reorientación de la cultura. Carlos Monsiváis, citado por García Canclini (1995, p. 135), afirma que los ciudadanos (en su caso, los mexicanos) aprendieron a reconocerse como un todo integrado, por encima de las fracturas étnicas y regionales.

\subsection{Análisis respecto de las personas con diversidad funcional}

La concepción de la discapacidad ha sufrido varios cambios a lo largo de la historia colombiana. Uno de los puntos de mayor complejidad ha sido la percepción que tiene la sociedad respecto de las personas con discapacidad para 
ejercer de manera idónea sus derechos, es decir, que estos se materialicen.

En consecuencia, la Sentencia de la Corte Constitucional C-066 del 2013 aborda el estudio de la discapacidad desde la perspectiva del modelo social que supera un modelo centrado en el asistencialismo, como un cambio de paradigma de la apreciación de discapacidad que adopta el reconocimiento de las personas con discapacidad como sujetos de especial protección, y el respeto por su diferencia. Dicha perspectiva pretende adaptar políticas públicas que tengan como obligación la previsión, rehabilitación e integración de las personas con discapacidad en la sociedad para su participación dentro de ella.

Desde un enfoque diferencial, las políticas públicas buscan comprender las diversas necesidades de las personas con discapacidad y el pleno desarrollo de sus capacidades, lo cual permite, de manera integral, generar mejoras a nivel social, buscando eliminar las barreras generadas por la exclusión.

La evolución de la percepción de discapacidad se puede ver a partir de la Sentencia T-109 de 2012 de la Corte Constitucional, en la cual surge el concepto de diversidad funcional, enfocado a establecer medidas que:

(i) permitan al mayor nivel posible el ejercicio de la autonomía de la persona con discapacidad; (ii) aseguren su participación en todas las decisiones que los afecten; (iii) garanticen la adaptación del entorno a las necesidades de la persona con discapacidad; y (iv), aprovechen al máximo las capacidades de la persona, desplazando así el concepto de "discapacidad" por el de "diversidad funcional". (Sentencia T-109, 2012). 
Así pues, el tema de las personas con discapacidad se debe abordar desde un modelo social, entendiendo la discapacidad no como una enfermedad sino como una realidad social que se debe asumir desde la diversidad, aceptando la diferencia como principal reto de la sociedad.

Tal como se establece en la Sentencia C-458 del 2015 de la Corte Constitucional, la mayoría de las dificultades por las que pasan las personas con discapacidad no se debe ni siquiera a su discapacidad física, sensorial o psíquica, sino, como lo expone la Sentencia C-006 del 2013 de la Corte Constitucional, a que la sociedad no se encuentra preparada para satisfacer las necesidades de todas las personas que la componen.

Además, el modelo social, tal como establece la Corte Constitucional en la Sentencia C-458 del 2015, permite que, dadas las dinámicas de inclusión y reconocimiento que se empiezan a generar en torno a él, la sociedad se empiece a adaptar a las necesidades de las personas con discapacidad, sin que estas tengan la obligación de ajustarse a la sociedad $\mathrm{y}$ a su entorno.

Así pues, es deber del Estado y de la sociedad hacer que todos los espacios sean idóneos y accesibles para que las personas con diversidad funcional hagan parte de manera efectiva dentro de la sociedad, que se genere una participación social idónea en donde no sean vulnerados los derechos fundamentales de este grupo poblacional.

Aun cuando el modelo social se ha venido implementando en Colombia a través de la jurisprudencia constitucional, de la Convención de Derechos de las Personas con Discapacidad y de la diferente normatividad que protege a las personas con diversidad funcional, el reconocimiento de derechos de este grupo poblacional no se ve materializado 
en su totalidad. Uno de los motivos es que la sociedad tiene todavía una concepción errónea de este grupo poblacional, como se mencionó anteriormente; se les ve desde un modelo médico, asistencialista y desde la enfermedad, no desde la diversidad, la igualdad y la capacidad, como debería ser. El panorama ideal sería donde se les conciba desde una realidad diferente, donde se adviertan sus necesidades y se realice un reconocimiento de su dignidad dentro de un colectivo, como lo advierte la Convención de los Derechos de las Personas con Discapacidad (onu, 2006).

\section{5. \#ClicSocial, un paso hacia la transformación}

Frente a la problemática antes descrita, las nuevas tecnologías, los medios de comunicación y las redes sociales juegan un papel importante en la promoción de los derechos de las personas con discapacidad o diversidad funcional y en la materialización de una igualdad y un reconocimiento de sus capacidades. Estos aspectos se proyectan como acciones positivas donde se genera un cambio ideológico efectivo a nivel colectivo y permiten una concientización dentro de la sociedad respecto a temas de inclusión, igualdad y acceso a las personas con discapacidad.

Las nuevas tecnologías fomentan la accesibilidad universal, la cual hace referencia a:

la condición que deben cumplir los entornos, procesos, bienes, productos y servicios, así como los objetos o instrumentos, herramientas y dispositivos, para ser comprensibles, utilizables y practicables por todas las personas en condiciones de seguridad, comodidad y de la forma más autónoma y natural posible. (Fundación Adecco, 2017, p. 15) 
Lo anterior con el fin de que estas personas puedan vivir en forma independiente y participar plenamente en todos los aspectos de la vida (onU, 2006), según como lo establece la Convención de la onu sobre los Derechos de las Personas con Discapacidad.

En este sentido, las nuevas tecnologías permiten mayor facilidad y autonomía ${ }^{2}$ en la realización de las diferentes actividades que desarrollan las personas con discapacidad. Por ejemplo, mejoran su calidad de vida por medio de la producción de empleos, superando todo tipo de barreras impuestas por la sociedad, a través de aplicaciones basadas en pictogramas intuitivos para personas con discapacidad intelectual, teletrabajo si existe una dificultad de desplazamiento, lectores de pantalla, impresoras de braille, determinadas adaptaciones tecnológicas y apps que solventan las barreras de la comunicación; como también la existencia de aplicaciones para denunciar violaciones de derechos humanos.

2 Autonomía entendida no como el poder hacer las cosas solo, sino de tener la posibilidad de tomar decisiones propias. Elegir cómo querer vivir, lo cual va encaminado al efectivo desarrollo de la dignidad humana. La Convención de la ONu sobre los Derechos de las Personas con Discapacidad establece en su artículo $3^{\circ}$ la autonomía individual como un principio general, incluida la libertad de tomar las propias decisiones, la independencia de las personas, el respeto por la dignidad inherente, etc.

Desde Kant, la autonomía de la voluntad es un precepto esencial para la moral, en donde la libertad es el principal fundamento. Es entonces como Kant parte de los "imperativos categóricos", los cuales expresan autonomía y universalidad. La primera indica que cada hombre imparte sus propias reglas basándose en la libertad y autodeterminación, y la segunda llevando a la inclusión de todos los seres racionales, entendiendo como categórico la no condicionalidad a ningún fin determinado, de aquellas proposiciones que declaran la realización de un hecho necesario, es decir, los hombres son autores de sus propias leyes, por tanto, le conceden al hombre una dignidad humana absoluta. Es decir, la autonomía le otorga al ser humano su propia esencialidad a través de la acción personal basada en la deliberación, la autorregulación y la decisión (Kant, 1785). 
Es decir, las nuevas tecnologías se convierten en un factor que permite la inclusión social (Fundación Adecco, 2017).

En Colombia, a través de las Tic se ha fomentado la participación de las personas con discapacidad, generando herramientas para derribar brechas sociales y darles una oportunidad de trabajo, educación y buena información a millones de personas con discapacidad (Corporación Colombia Digital, 2012).

Sin embargo, más allá de lo anterior, para lograr una verdadera inclusión es necesario que todas las personas se vuelvan consientes de la diversidad que caracteriza la vida en sociedad y, es aquí donde los medios de comunicación y las redes sociales cumplen un papel importante.

En la actualidad, se puede observar que es la sociedad misma la que empieza a reconocer la población con discapacidad y en consecuencia reconoce todas las barreras que afronta. La sociedad empieza a crear acciones en aras de generar conciencia y reconocimiento colectivo de derechos desde la diversidad para las personas con discapacidad, las cuales se han podido replicar a partir de los diferentes medios de comunicación ahora existentes y de las redes sociales.

Un ejemplo claro de esto fue la convocatoria para el Censo Nacional de Población y Vivienda del 2018, en la que se reconoció que por falta de recursos se excluirían preguntas sobre información básica de personas con discapacidad, tales como afiliación y atención en salud, generando así desigualdad y poca accesibilidad. En este sentido, Juan Pablo Salazar, del movimiento por los derechos de las personas con discapacidad, expresa que:

[...] no se pueden generar políticas públicas en razón de la diversidad funcional sin contar con datos y diagnósticos 
que expresen de manera concreta las condiciones en las que se encuentran las personas con discapacidad; aproximadamente tres millones de personas quedarían por fuera del Censo Nacional, de manera que generaría poca asertividad y confusión al momento de trabajar en función de garantías de las personas con discapacidad y conocimiento de situaciones actuales en las que se encuentran las personas con diversidad funcional. (Salazar, 2018)

Lo anterior haría más difícil la inclusión social.

En este sentido, a través del Laboratorio de Derechos económicos, sociales y culturales (DescLAB), se realizan dos iniciativas denominadas \#E1CensoEsDeTodos (2018) y \#CuentanosParaQueContemos (2018), las cuales combinaron "herramientas jurídicas, de medios de comunicación, de participación social y de movilización digital para lograr que las cuatro preguntas sobre discapacidad no fueran excluidas del Censo 2018" (DescLAB, 2018).

Dichos hashtags se volvieron tendencia. En la primera Twitteratón \#E1CensoEsDeTodos (2018) logró 10600 tuits en menos de una semana, y esto provocó el pronunciamiento del presidente de Colombia, Juan Manuel Santos Calderón, a través de su cuenta oficial de Twitter, a través de la cual se vinculó a políticos, periodistas, medios de comunicación e influencers.

Lo anterior refleja la toma de conciencia ante el perjuicio irremediable que se podría ocasionar a las personas con discapacidad con la omisión por parte del DANE. Al excluirlas "de la más importante herramienta de recolección de información estadística y demográfica del Estado y la sociedad colombiana" se les condena a la invisibilidad, aun más cuando a través del Censo Nacional se establecen las 
prioridades públicas, la focalización de territorios y la distribución de la inversión pública (DescLAB, 2017).

Es evidente cómo la sociedad se encuentra en discrepancia con la invisibilización de las personas con discapacidad y se genera dicha movilización a través de redes sociales con el fin de que se reflejen las necesidades de este grupo que goza de especial protección constitucional para que sean prioridad para el Estado. Finalmente, gracias a esto y a las acciones jurídicas que desde DescLAB se impetraron ante el DANE, se logró que esta minoría fuera incluida en el Censo Nacional de Población y Vivienda del 2018.

Con esto se refleja cómo desde la participación informal se genera movilización y acción colectiva como una nueva forma de expresión y participación que se pone en función cuando los métodos de participación tradicionales no generan resultados satisfactorios.

El uso de las nuevas tecnologías y redes sociales, en concordancia con la movilización social masiva de manera proactiva, genera resultados afirmativos frente a la visibilización de la diversidad funcional. Esto además genera inclusión social a través de acciones que permiten cambiar los imaginarios que se tienen respecto de la discapacidad y ampliar la perspectiva. A continuación, algunas muestras de ello.

Antonio Centeno y Raúl De la Morena, activistas del Movimiento de vida independiente, movimiento social y político en aras de la diversidad funcional, y directores del documental denominado $;$ Yes, we fuck!, realizan una reflexión respecto de la sexualidad diversa con el fin de poner un foco en la diferencia, como lo es la diversidad funcional. Con él buscan desmitificar temas como el sexo, el género, los órganos genitales, entre otros; y más aún, con el fin de derribar la errónea idea consistente de considerar a las personas con 
discapacidad como personas asexuales, de liberar los discursos y estereotipos que se han generado sobre los cuerpos y la sexualidad y, por el contrario, de mostrar que se trata de una sexualidad más rica, más diversa, más allá de la que se impone dentro de la sociedad (De la Morena y Centeno, 2016). Dicho documental ha obtenido millones de reproducciones a través de medios de comunicación y redes sociales, y ha contado con reconocimiento a nivel internacional.

A partir de este proyecto se desarrolla un portal virtual denominado asistenciasexual.org, promovido por los mismos directores. Este busca brindar apoyo a las personas con discapacidad respecto de la sexualidad y pretende que las sociedades tengan una idea más realista e interesante de lo que es e implica la sexualidad (De la Morena y Centeno, 2016). Estos aspectos implican avances en las brechas generadas por la sociedad frente a las personas con discapacidad.

Aun con la alta difusión que han alcanzado dichas estrategias, las cuales finalmente buscan la materialización de la inclusión social, dadas las grandes posibilidades que ofrecen los medios de comunicación y las redes sociales, Yaiza Redlights, a partir de su influencia e incidencia a través de la plataforma virtual YouTube, aborda el tema de la discapacidad desde la asistencia sexual, diversidad funcional y legalidad, influenciando a miles de personas que la siguen y a quienes ocasionalmente se topan con sus trabajos, en especial con el video llamado "Diversidad funcional y feminismo \#LaComplejaRealidad"(2017). Este afianza la idea de que todos los cuerpos son diferentes, funcionan de manera diferente y gozan de manera diferente, lo cual genera reflexión frente a la diversidad funcional y consciencia colectiva frente a la necesidad de cambios. 
Por otra parte, las plataformas virtuales también son herramientas para que las personas con diversidad funcional hablen acerca de la inclusión y de cómo esperan ser reconocidas en una sociedad. Según Majo es un canal de la plataforma virtual Prensa.com de México, el cual es desarrollado por una adolescente con síndrome de Down que muestra que las problemáticas que tienen las personas con discapacidad se dan por las falsas creencias y las barreras que impone la sociedad. Ella pretende que a través de su canal todas las personas aprendan y se den cuenta de que la discapacidad hace parte de la realidad y que la forma en la que se aborda depende de todos.

La participación de las personas con discapacidad en actividades de recreación, como las obras de teatro realizadas en la ciudad de Manizales, Caldas, desde la compañía Pata de conejo, busca la exploración del arte visual comprendido desde la discapacidad, potencializando sus capacidades he incluyéndolos en las actividades cotidianas realizadas en una sociedad; además de ser una herramienta innovadora, la participación ha sido inculcada a partir de redes sociales, donde se invita a la población a hacer parte de dichos proyectos y a aprender de otra realidad que desconoce.

Como otra forma de movilización social, se encuentra la iniciativa denominada \#NoMásTeletón, justificada en que Teletón no busca un avance en la garantía de derechos para las personas con discapacidad, ni el reconocimiento de sus capacidades, sino, por el contrario, se reconoce desde lo vulnerable y retrocede respecto de la igualdad; al adoptar un concepto basado en un modelo asistencialista, vulnera y atenta contra la dignidad de las personas con discapacidad. Dicha iniciativa se basa en el lema: "Nuestras capacidades no se venden”; así, pues, sus derechos deben ser garantizados 
por parte del Estado a través de acciones que permitan materializar una igualdad (\#BrigadaDigital, 2017).

Estas son algunas de las expresiones que se hacen a través de medios digitales para generar acciones de inclusión. En ellas se hace uso legítimo de la participación activa por medio de mecanismos no formales, pero que generan grandes cambios en los imaginarios sociales. Es evidente cómo la influencia positiva frente a las causas sociales genera avances significativos frente al reconocimiento y visibilización de la diversidad funcional.

\section{Metodología}

Al tratarse de un artículo de carácter cualitativo, se establece una perspectiva holística del tema, teniendo como propósito describir, comprender e interpretar los diferentes fenómenos que se puedan presentar en torno a la participación digital como mecanismo de inclusión social. Esto a través de la valoración de procesos, experiencias y puntos de vista que permitan examinar el mundo social para desarrollar un análisis coherente con lo que se observa.

Además, se aborda desde un paradigma crítico-social, en tanto se vincula el conocimiento social a la posibilidad de transformar la realidad. Implica conocer la problemática, reflexionar sobre la realidad y accionar para transformarla. El análisis de la información se hace desde un proceso de diálogo, reflexión crítica y confrontación de la relación de los hechos y su historia, de los hechos y la teoría que los explica, de los hechos y sus consecuencias.

Las técnicas para recolectar datos fueron: la observación, los documentos y la discusión en grupo. 


\section{Conclusiones}

La herramienta más poderosa que se tiene para combatir las irregularidades o exclusiones en una sociedad es, sin lugar a duda, los movimientos sociales que buscan influenciar a la sociedad de manera positiva, generando acciones inclusivas, pese a las inconsistencias que existen en las esferas del poder.

La sociedad da pasos agigantados hacia las nuevas tecnologías y con esto permite la inclusión desde el lenguaje para crear una realidad donde se participe de diferentes formas y se desestigmaticen los calificativos negativos, no solo desde el mejoramiento de los conceptos que se tienen sobre la discapacidad, sino también desde la transformación de la mirada cultural que defiende el derecho a la diferencia, a la diversidad y a la libertad.

Las nuevas tecnologías, los medios de comunicación, las redes sociales y plataformas virtuales son el hilo conductor que potencializa la diferencia de manera positiva en las personas con diversidad funcional, como se pudo soportar en este trabajo.

Sin embargo, no se trata solo de visibilizar, sino de mostrar cómo se hace. No se trata de sensibilizar, sino de generar un cambio de mentalidad. Debe existir una modificación en la manera como se mira al otro, en mirar de igual a igual, y es ahí donde se genera un cambio real.

De cualquier forma se puede iniciar con pequeños cambios como: fomento de empleo, fomento de la permanencia en instituciones educativas, aprendiendo lenguaje de señas, siendo voluntario, respetando las zonas azules, rampas y demás sitios, y utilizando los términos verbales adecuados que demuestren la importancia del lenguaje para crear la realidad. Sin embargo, no basta con cambiar los conceptos, 
se trata de cambiar la mirada, el pensamiento y de tomar una decisión para el cambio.

En este sentido, la sociedad colombiana tiene como retos modificar currículos en las instituciones educativas para que sean incluyentes y generen reconocimiento de la diversidad; así como también tienen una corresponsabilidad ciudadana que permita una participación y reconocimiento pleno de las personas con diversidad funcional, por ejemplo a través de la desmitificación de sus derechos sexuales y reproductivos, su capacidad y autonomía, dando paso de esta forma a la materialización de un modelo social de la discapacidad que genere herramientas para evitar el asistencialismo y reconozca efectivamente los derechos fundamentales.

Es importante que frente a la discapacidad se realicen estudios interdisciplinares, teniendo en cuenta que este no es un tema que se deba analizar e intervenir específicamente desde lo jurídico o médico, por el contrario, la sociedad en general debe permitir que se potencialicen las capacidades de las personas con diversidad funcional para que puedan participar de manera activa dentro de la sociedad.

Sería pertinente mencionar el siguiente adagio: "ha sido establecido científicamente que el abejorro no puede volar, según las leyes de la aerodinámica, sencillamente no lo puede hacer. Pero como nadie se lo ha dicho, el vuela". Esto es, la persona con discapacidad es quien debe tener los medios para tomar sus propias decisiones y hacer parte de la sociedad en igualdad de condiciones, sin que exista un impedimento por parte del Estado o de la sociedad para realizar sus actividades, disfrutar de su vida y dignificarla.

Lo anterior empieza a ser posible cuando se deja de ver la discapacidad como una enfermedad y se comprende que se trata de una relación con el entorno y no con la persona. 
La tecnología facilita dicho cambio y permite ir evolucionando sucesivamente la cultura de discriminación.

El reto es entonces seguir haciendo uso de estas herramientas que ofrece o brinda la tecnología, y tener en cuenta que una voz, unida con el resto, tiene un gran impacto.

Y, tal como lo estable Jorge Aguirre en La ciudadanía mediática, teniendo en cuenta que las redes sociales se refieren a las redes de tipo electrónico, se deberían denominar redes sociales cibernéticas, en tanto alrededor de 1830 el término cibernétique en Francia hacía referencia al arte de gobernar. Por esto se debería regresar a las redes sociales su sentido etimológico original y convertirlas en los instrumentos del arte de gobernar.

\section{Referencias}

Asistenciasexual.org (s. f.). Asistenciasexual.org. Recuperado de https://asistenciasexual.org

\#BrigadaDigital (enero del 2017). \#NoMásteleton. Recuperado de http://www.brigadadigital.com.co/

Congreso de la República (2013). Ley 1618 del 2013.

Corte Constitucional (2015). Sentencia C-458 del 2015.

Corte Constitucional (2013). Sentencia C-066 del 2013.

Corte Constitucional (2012). Sentencia T-109 del 2012.

Corporación Colombia Digital (2012). TIC para la inclusión social. Una apuesta por la diversidad.

Correa, L. (2008). Litigio de alto impacto. Estrategias alternativas de ejercer el Derecho. Revista de Derecho, 7(14).

Dahlgren, P.(2005). The Internet, public spheres and political communication: Dispersion and Deliberation. Political Communication.

De la Morena, R., \& Centeno, A. (abril del 2016). Ciclo de cine, secualidades en plural. Recuperado de http://www. 
accionenredasturies.org/upload/Ficha\%20de\%20debate\%20Yes,\%20We\%20Fuck!.pdf

DescLAB (2017). Comunicado de prensa: Acción de tutela en contra del DANE para proteger los derechos de las personas con discapacidad. Recuperado de \#CuéntanosParaQueContemos https://docs.wixstatic.com/ugd/e0e620_621 765b67c394a1989397b6f2fd002e1.pdf

DescLAB (2018). Laboratorio de derechos económicos, sociales y culturales. Recuperado de www.desclab.com/cuentanos Fundación Adecco (2017). Tecnologías y discapacidad. Recuperado de https://fundacionadecco.org/wp-content/ uploads/2016/07/Informe-Tecnolog\%C3\%ADa-yDiscapacidad.-Fundaci\%C3\%B3n-Adecco-y-Keysight2017.pdf

García Canclini, N. (1995). Consumidores y consumidores. Conflictos multiculturales de la globalización. México: Editorial Grijalbo.

GLoobal (s. f.). Movimiento Ciudadano por la Democracia (MCD). Recuperado de http://www.gloobal.net/iepala/gloobal/ fichas/ficha.php?entidad=Agentes\&id=4244\&opcion= descripcion

Grupo en Derecho Constitucional - DERco. Línea de investigación en Derechos Fundamentales (2015). Clínica jurídica en acciones de interés público en materia de discapacidad con enfoque de diversidad funcional e inclusión social. Pereira: Universidad Libre.

Kant,I.(1785). Fundamentación de la metafísica de las costumbres. Kymlicka, W., \& Norman, W. (agosto de 2002). El retorno del ciudadano. Una revisión de la producción reciente en teoría de la ciudadanía. Obtenido del Instituto de Estudios Peruanos. Taller Interactivo: Prácticas y Representaciones de la 
Nación, Estado y Ciudadanía en el Perú. Recuperado de https://www.insumisos.com/lecturasinsumisas/kymlicka. pdf

onu (2006). Convención de los Derechos de las personas con Discapacidad.

Salazar, J. P. (2018). Denuncian exclusión de personas en condición de discapacidad en el censo nacional 2018 [N. $\mathrm{RCN}$, entrevistador].

Yes, we fuck! (2015). Yes, we fuck! Recuperado de http://www. yeswefuck.org/ 
Este libro fue compuesto en caracteres Adobe Caslon

Pro 11,2 puntos, impreso en 2018, en Bogotá, D. C., Colombia

Xpress. Estudio Gráfico y Digital S.A.S. 